\title{
A Statistical Model for Stock Assessment of Southern Bluefin Tuna with Temporal Changes in Selectivity
}

\author{
D. S. Butterworth , J. N. Ianelli \& R. Hilborn
}

To cite this article: D. S. Butterworth , J. N. Ianelli \& R. Hilborn (2003) A Statistical Model for Stock Assessment of Southern Bluefin Tuna with Temporal Changes in Selectivity, African Journal of Marine Science, 25:1, 331-361, DOI: 10.2989/18142320309504021

To link to this article: http://dx.doi.org/10.2989/18142320309504021

曲 Published online: 08 Jan 2010.

Submit your article to this journal $₫$

Џll Article views: 146

Q View related articles $\llbracket$

Citing articles: 19 View citing articles 
Afr. J. mar. Sci. 25: 331-361

2003

\title{
A STATISTICAL MODEL FOR STOCK ASSESSMENT OF SOUTHERN BLUEFIN TUNA WITH TEMPORAL CHANGES IN SELECTIVITY
}

\author{
D. S. BUTTERWORTH*, J. N. IANELLI† and R. HILBORN
}

\begin{abstract}
Assessment of the status of southern bluefin tuna (SBT) by Australia and Japan has used a method (ADAPT) that imposes a number of structural restrictions, and is similar to methods used for a number of stocks worldwide. A flexible method for assessment of the SBT population is presented that is much less restrictive and has potentially wide applicability. The three key features are: (1) all fitting to data is within the context of maximum likelihood, (2) catch-at-age data are not assumed to be without error (as in existing methods), but rather to be random variables, while age-specific selectivity is allowed to change over time within the bounds of specific structure, and (3) autocorrelation in recruitment processes is considered within the likelihood framework of the model. While the results suggest the stock has been depleted considerably from its virgin biomass, and are generally consistent with previous assessments, they also indicate that it is not as much below the biomass that will produce maximum suitable yield as previously estimated and that the extent of stock rebuilding necessary may not be as large as has been argued. The available data are shown to provide little information on the steepness parameter of the stock-recruitment function, and hence on sustainable catch levels for the stock.
\end{abstract}

Key words: ADAPT-VPA, assessment, catch-at-age analysis, recruitment auto-correlation, selectivity changes, southern bluefin tuna, steepness, time-series model

Management actions and initiatives for bluefin tuna over the past decade have been the subject of considerable controversy. Debate has centred particularly on stocks of the north Atlantic Thunnus thynnus, especially in the western North Atlantic, and of the southern hemisphere (southern bluefin tuna [SBT] Thunnus maccoyii). In 1992, a proposal was made to list the western North Atlantic bluefin population on Appendix I of the Convention governing International Trade in Endangered species (CITES). The proposal was subsequently withdrawn, but had it succeeded, would have resulted in a cessation of international trade in catches from that population. More recently, the status and management of SBT has been at issue in the first case of its kind brought (by Australia and New Zealand against Japan) before the International Tribunal for the Law of the Sea (ITLOS) during 1999; this case centred on the implications of alternative interpretations of catch per unit effort (срие) information for stock status and trends. There is no doubt that, for both these populations, the spawning stock declined appreciably over recent decades, with excessive catches certainly responsible to some extent. What is less clear is the magnitude of these declines, and also whether or not management action taken in the 1980s to reduce catches has led to, or provides prospects for, any meaningful recovery.
A particular problem in the assessment of these stocks arises because, at least until recently, direct ageing of bluefin tuna has not been possible. The catchat-age data used as input to age-structured assessment models have had to be derived from length distribution information by the rather crude method of cohort slicing, based on growth curves developed mainly from tag-recapture records. Because annual growth decreases with age, age distribution data cannot be determined with great accuracy at older ages. Accordingly, the ADAPT-VPA (Gavaris 1988) assessment models, which have been applied to SBT and North Atlantic bluefin tuna (e.g. Geromont and Butterworth 2001), and which make the assumption of error-free catch-at-age data, have required the pooling of data for the older ages into a single plus-group at a relatively young age, thereby ignoring any information that these data may contain. This is unfortunate because the assessed size and recent trends in these plus groups dominate perceptions of the current health of these resources in terms of recent and prospective trends in spawning biomass, so any uncertainties in estimates for the plus-group have a marked impact on perceptions of overall resource status and prospects.

In this paper an age-structured assessment method, which does not require the assumption of error-free catch-at-age data, is applied to SBT. The particular

\footnotetext{
* Marine Resources Assessment and Management Group, Department of Mathematics and Applied Mathematics, University of Cape Town, Rondebosch 7701, South Africa. E-mail: dll@maths.uct.ac.za

$\dagger$ NMFS Alaska Fisheries Science Centre, 7600 Sand Point Way NE, Seattle WA 98115, USA

\$ Fisheries Research Institute, University of Washington, Seattle WA, 98195, USA
}

Manuscript received January 2003; accepted March 2003 
aims are to determine whether such an approach can produce an improved assessment of the resource; how the results of this assessment compare to those of the ADAPT procedure previously applied, given the somewhat ad hoc constraints that that procedure has had to impose upon selectivity patterns for Ages 9 and above; and what extent of stock rebuilding is needed.

The paper presents a statistical approach that builds upon the analysis Hilborn and Butterworth (1996) tabled at the 1996 meeting of the Scientific Committee (SC) of the Commission for the Conservation of Southern Bluefin Tuna (CCSBT). The basic method is described in sections of the review article by Punt and Hilborn (1997) dealing with age-structured models. The essential novel features of these analyses in relation to previous assessments of SBT are:

1. Model calculations begin in 1951, close to the start of the fishery, so rendering assumptions that relate commencing numbers-at-age to pre-exploitation conditions (though nevertheless allowing for fluctuations about a deterministic equilibrium agestructure) rather more plausible than those for traditional approaches within the CCSBT SC, which commenced calculations in the 1960 s after substantial catches had already been taken from the resource.

2. The analyses incorporate data on the age distribution of the spawning stock and extend the model to include ages up to 30 (which is treated as a "plus" group). Previous methods used by Japanese and Australian scientists in the CCSBT SC consider an Age 12+ group, and have frequently made some assumptions about the relationship between fishing mortality on Ages 11 and 12+. With recent direct ageing studies by Gunn et al. (1996) indicating that SBT can live to some 40 years of age, rather than the 20 years or so considered earlier, and hence that there are far more age-classes present in the 12+ component of the population than had previously been thought, assumptions that the relative selectivities for these two age-groups are closely related become much less plausible. To the contrary, a ratio quite different from 1 , which changes markedly as the age distribution of the $12+$ fish responds to variations in recruitment and fishing mortality, would be expected.

3. The analyses use a likelihood-based statistical catchat-age approach. This type of approach is common in many U.S., New Zealand and Australian fishing assessments. The application of the ADAPT approach (Gavaris 1988) is unique to SBT among the major fisheries in Australia.

4. The stock-recruitment relationship is estimated within the model-fitting process, rather than from model outputs, and takes serial correlation in residuals into account. This is a more consistent approach to estimating a key component of the process required for computing projections to aid management advice.

5. The analyses have been developed using AD Model Builder software, which allows for highly efficient and flexible estimation to evaluate the support that the data provide for alternative hypotheses about current abundance and depletion levels.

6. The statistical model allows the assumption that catch-at-age data are measured without error to be dropped. As indicated above, that assumption may be particularly open to question, given that the catch-at-age data are derived by the crude method of cohort slicing.

The basic approach underlying this analysis follows the concepts outlined in Fournier and Archibald (1982) and expanded on by Haist et al. (1993) and others (e.g. Fournier et al. 1998). Specifically, the model presented below differs from traditional VPA because estimates of catch numbers-at-age are treated as observations with error (rather than assuming that they are known exactly). Additionally, the current model differs from CAGEAN (Catch AGE Analysis; Deriso et al. 1985) and other related approaches (e.g. stock synthesis; Methot 1990) because of greater flexibility in the treatment of gear selectivity and the types of errors that can be modelled.

\section{DATA}

\section{Background}

SBT are found exclusively in the southern hemisphere. Only one spawning ground has been identified, in an area between Java, Indonesia and north-west Australia, so the resource is considered to be a single stock. Juveniles migrate southwards along the west coast of Australia, and congregate in the coastal waters of the southern part of Australia, particularly from December to April, where they are subject to a local purse-seine fishery (Caton 1991). As the fish age beyond some three years, their distribution starts to extend widely into not only the Indian but also the Atlantic and Pacific oceans. The Japanese longline fishery for SBT at first operated on the spawning grounds, but later shifted to concentrate in feeding areas in the $40-50^{\circ} \mathrm{S}$ band.

The history of the SBT fishery (see also Polacheck et al. 1999) is summarized by plots of the annual catch, by weight and number (Fig. 1). A decline in the annual 


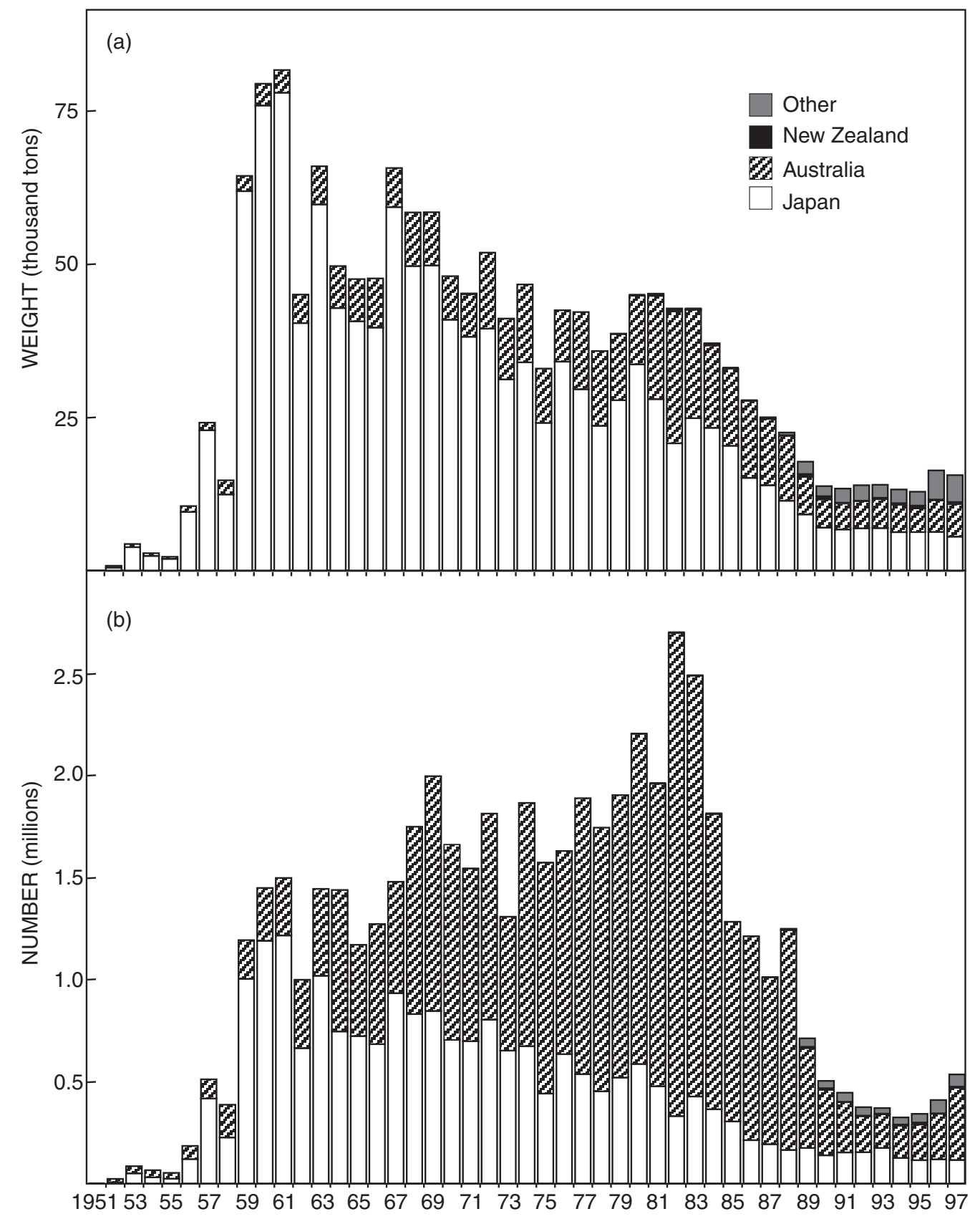

Fig. 1: Annual catch of SBT by (a) weight and (b) number for different fleets 


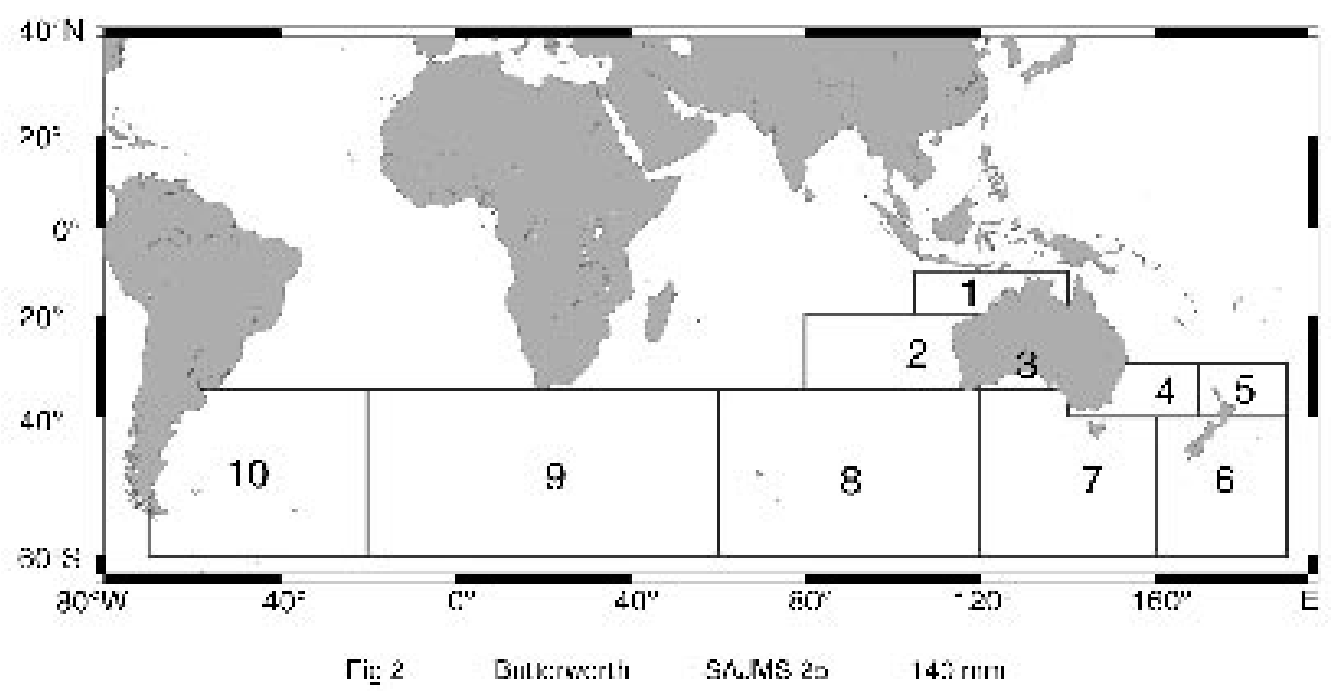

Fig. 2: Map showing the management Areas for SBT, as designated by the CCSBT

catch by weight during the 1980 s was followed by a Total Allowable Catch (TAC) limitation on the combined Australia-Japan-New Zealand catch from 1990. The catch made by countries other than these three (i.e. nations that were not members of the CCSBT at that time) has increased sharply over the past few years. Although Japan's has remained the largest share of the catch by mass, Australia's proportion of the catch by number was particularly high over the 1970s and 1980s, given the development of a local purseseine fishery that concentrated upon young (typically 1-4 year-old) tuna.

The data used in the analyses that follow are as reported at the 1998 meeting of the CCSBT SC.

\section{Fishery-related}

Catch-at-age data from 1951 to 1997 for Ages 1-19, and a plus-group consisting of all fish of Age 20 and more were kindly provided by S. Tsuji and Y. Takeuchi (National Research Institute of Far Seas Fisheries, Japan). These are available separately for different components of the fishery. The analyses of this paper distinguish the Japanese longline fishery from the balance of other operations. The Japanese longliners have operated in a relatively consistent manner over time in the more southerly management Areas 3-9, as designated by the CCSBT (see Fig. 2). Areas 3-9 run from longitude $20^{\circ} \mathrm{W}$ through the eastern hemisphere to $170^{\circ} \mathrm{W}$; their northern boundary is $35^{\circ} \mathrm{S}$, except that this changes to $30^{\circ} \mathrm{S}$ east of Australia. The inclusion of Area 3 adds the Great Australian Bight to the overall region. Although formally these areas extend to Antarctica, fishing hardly extends farther south than $50^{\circ} \mathrm{S}$.

The basis for the development of the catch-at-age matrices is detailed in Polacheck et al. (1997a). Age distributions are derived from estimated annual length distributions of the catch by cohort-slicing, taking account of an increase in somatic growth over the period considered. The procedures by which pre-1965 length distributions were developed are not fully documented, so the associated estimates of age distributions are considered less reliable than those for later years. Attempts have been made when constructing these matrices to make allowance for catches by nations that were not members of the CCSBT, and for discarding.This process, together with a weight-at-length relationship, provides the weight-at-age matrix (Polacheck et al. 1997b) used in these analyses to compute spawning biomass.

Cриe indices of abundance by age-group have been developed from longline operations for the period 1969-1997 (see Polacheck et al. 1997b, Polacheck and Preece 1998). The indices are standardized by GLM methods to provide indices of fish density on a $5^{\circ}$ square basis. In integrating such density estimates over area, and averaging over months, so as to index overall abundance, assumptions are required to esti- 
mate the catch rates in the $5^{\circ}$ squares not fished in a particular month and year. Series corresponding to three such sets of assumptions are considered here (from Tables 3a, b and d of Polacheck and Preece 1998):

(i) "Constant squares": the catch rate in those squares not fished in a particular month and year is set equal to the average rate in the squares that were fished in that year;

(ii) "Variable squares": the catch rates in the squares not fished in a month and year are taken to be zero; and

(iii) "Geostatistical": geostatistical methods (spatial models) are used to estimate the catch rates in the squares not fished. The "geostatistical" approach gives results intermediate between the other two, and the associated age-specific cpue series are used for the "Reference case" assessment following.

The particular age-groupings used in fitting the population model to these data (viz. 4, 5, 6-7, 8-11 and $12+$ ) were selected by the CCSBT SC with a view to robustness to sampling and ageing error. Ideally, separate series for each age would be used, but the cohort-slicing method becomes increasingly inaccurate with age because the somatic growth rate slows. Сриe values for Age 4 for two recent years of the assessment (1995 and 1996) are excluded because of comparability concerns arising from the practice adopted of returning live tuna of $<25 \mathrm{~kg}$ to the sea during this period.

\section{Auxiliary information}

Line-transect aerial surveys of surface schools in the Great Australian Bight provide indices of abundance for juvenile SBT. For reasons discussed in Polacheck et al. (1997b), the most reliable index available from these data is considered to be that for 3-year olds at the start of the year, from 1993 to 1998 (though the results for 1998 are not used for the assessments of this paper, which extend only to 1997). The associated biomass estimates and standard errors used are those for the entire Australian Bight, as reported in Table 6.4 of Cowling and Millar (1998). (More recently, however, various concerns have arisen about the comparability of these data over time, including the question of whether spotter efficiency has remained constant [Gunn et al. 2001]).

Gunn et al. (1996) report results for direct ageing of samples from the SBT spawning stock in 1994/95 and 1995/96. The analyses that follow fit to the average of the two distributions reported, because these were derived from the same age-length key based on readings of samples taken in both these spawning seasons.
Tagging experiments on young fish were conducted during the 1990s, with the number of animals tagged, and subsequent recoveries, summarized by age in Table 5 of Polacheck and Preece (1998). Incorporation of these data into an assessment process requires assumptions to be made about the potentially very different rates of tag reporting for the different component fisheries, as discussed in Polacheck et al. (1997c, 1998). The Reference case assessment conducted here is based on the intermediate Model 5 of that paper, using the reporting rates by age and year as given in Table 4 thereof.

\section{THE MODEL}

\section{Overview}

Because the details of the model presented below are rather complex, an introductory overview is provided to assist readers.

Standard age-structured dynamics are used to model the population. Recruitment is related to spawning biomass by a Beverton-Holt functional form, although the annual residuals about this relationship may be serially correlated. The particularly novel aspect of the approach is the manner in which fishing mortality-atage is modelled or, to be more specific, constrained. First, fishing mortality is separated into two components: a dominant and steadier component arising from Japanese longline operations, and a more variable balance that accounts for all the other fisheries combined. Then each of these fishing mortalities-at-age is itself separated into two multiplicative components: a year and an age effect, where the latter corresponds to selectivity-at-age and may change over time. The approach restricts the extent of the changes with time that both of these effects may show, and also constrains the selectivity effect to vary smoothly with age.

The parameters of the model are fitted by minimizing an objective function. This is developed within a likelihood framework, for which the best fit is provided by minimizing the negative log-likelihood (which resembles the standard sum-of-squared errors formulation in many ways). The particular advantages of using a likelihood framework are that it provides a basis for according statistically defensible relative weightings to the different sets of data incorporated in the fitting process, and also that it readily allows for confidence intervals for model parameters to be estimated. The approach here does not, however, stick strictly to the frequentist statistical paradigm, because penalty terms are added to the negative loglikelihood in a manner motivated by the way in 
which prior information and constraints on parameters (through "random effects" models) would be incorporated in a Bayesian estimation context.

Inputs to this negative log-likelihood function include the data specified above, such as cpue, catch-atage and tagging information. However, penalty terms are included to impose constraints on the magnitudes of changes to the year and age effects into which the fishing mortalities-at-age are separated. Because such changes are estimable parameters of the model, the fitting process can require minimization over more than 100 parameters, so a particularly efficient algorithm is required.

ADAPT corresponds to a special case of this much more general framework, and the equivalences are explained.

The results of the analyses to follow will be shown to be strongly dependent on a parameter of the stock-recruitment relationship termed steepness ( $h$; Mace and Doonan 1988, Francis 1992). Steepness is defined as the fraction of pristine recruitment expected when spawning biomass is reduced to $20 \%$ of its pristine (average pre-exploitation) level. For compensatory monotonically increasing relationships, such as the Beverton-Holt form, steepness must lie between 0.2 and 1 . For a given natural mortality, the higher the value of steepness in this range, the larger the difference between recruitment and natural deaths when the population is reduced below its pristine level, and hence the larger the potential sustainable yield.

\section{Population dynamics}

The traditional assessment models used by Australian and Japanese scientists in the CCSBT SC have combined all fish of Age 12 and older, which precludes model fits to the Gunn et al. (1996) age data for spawners. Here a model is constructed that explicitly tracks individuals to Age 30 in an attempt to make use of these recent spawning age-distribution observations in the model-fitting process. The model equations are given below, but the essential differences between this model and the ADAPT models of Australian and Japanese scientists are the following:

- Calculations of numbers-at-age are made forwards from estimated recruitments rather than backwards from estimated terminal fishing mortalities $(F \mathrm{~s})$.

- Over-dispersed multinomial sampling errors in the estimates of catch-at-age data are assumed, rather than assuming that these data are error-free.

- The age structure is maintained up to Age 30+, instead of $12+$.

- Catch data commencing in 1951 when the fishery started, rather than 1969 as has been more customary in the CCSBT SC, are used, and all calculations begin in that earlier year. The initial 1951 numbers-at-age for ages up to 20 are estimated based on the extent to which the data provide information on deviations from deterministic equilibrium with respect to natural mortality, whereas those above Age 20 are taken to have their deterministic equilibrium levels. The deterministic equilibrium level is based on a Beverton-Holt stockrecruitment relationship (as customarily assumed by the CCSBT SC), the parameters of which are estimated in the overall fit to the data, as detailed below. Given that the deviations from equilibrium numbers-at-age in 1951 are permitted, the spawning biomass in 1951 may differ from the average preexploitation equilibrium level.

The model employed has a common population dynamics form. An explicit age-structured model is used with the standard catch equation as the underlying population model (e.g. Fournier and Archibald 1982, Deriso et al. 1985, Hilborn and Walters 1992, Schnute and Richards 1995). Predicted catch in numbers-at-age in year $t\left(C_{t_{a} a}\right)$ and total annual catch by weight $\left(Y_{t}\right)$ are modelled as:

$$
\begin{aligned}
& C_{t, a}=\frac{F_{t, a}}{Z_{t, a}}\left(1-\mathrm{e}^{-Z_{t, a}}\right) N_{t, a} \quad\left\{\begin{array}{l}
1 \leq t \leq T \\
0 \leq a \leq A
\end{array}\right. \\
& N_{t+1, a+1}=N_{t, a} \mathrm{e}^{-Z_{t, a}} \quad\left\{\begin{array}{l}
1 \leq t \leq T \\
0 \leq a \leq A-2
\end{array}\right.
\end{aligned}
$$

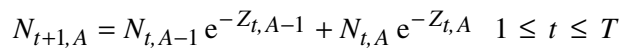

$$
\begin{aligned}
& Z_{t, a}=F_{t, a}+M_{a} \\
& C_{t, \bullet}=\sum_{a=0}^{A} C_{t, a} \\
& p_{t, a}=C_{t, a} / C_{t, \bullet} \\
& Y_{t}=\sum_{a=0}^{A} w_{t, a} C_{t, a}
\end{aligned}
$$

where

$T \quad$ is the number of years of fishing (i.e. $t=1$ corresponds to 1951 and $t=T$ corresponds to 1997),

$A \quad$ is the largest age considered $(A=30)$, which is treated as a plus-group,

$N_{t, a}$ is the number of fish Age $a$ at the start of year $t$, $C_{t, a}$ is the catch by number of Age $a$ in year $t$,

$p_{t, a}$ is the proportion of the total catch in year $t$ that is of Age $a$,

$C t$, is the total catch by number in year $t$, 
$w_{t, a}$ is the mean body weight $(\mathrm{kg})$ of fish of Age $a$ in year $t$,

$Y t$, is the total catch by weight in year $t$,

$F_{t, a}$ is the instantaneous fishing mortality for Age $a$ in year $t$,

$M_{a}$ is the instantaneous natural mortality for Age $a$, and

$Z_{t, a}$ is the instantaneous total mortality for Age $a$ in year $t$.

The freedom of the parameters listed above is reduced by restricting the variation in the fishing mortality rates $\left(F_{t, a}\right)$ by assuming that

$$
F_{t, a}=F_{t, a}^{1}+F_{t, a}^{2}
$$

with

$$
F_{t, a}^{f}=H_{t, a}^{f} G_{t}^{f}
$$

where $G_{t}^{f}=\bar{G}^{f}+\varepsilon_{t}^{f}$

$$
\varepsilon_{t}^{f} \sim N\left(0,\left(\bar{G}^{f} \sigma_{G}^{f}\right)^{2}\right)
$$

$$
H_{t+b, a}^{f}=H_{t, a}^{f} \exp \left(\gamma_{t, a}^{f}\right) \quad \gamma_{t, a}^{f} \sim N\left(0,\left(\sigma_{H_{t}}^{f}\right)^{2}\right) \text {. }
$$

$H_{t, a}^{f}$ is the age effect of fishing by fleet $f$ for Age $a$ in year $t$, normalized to average 1.0 over Ages $a=$ $0-A$,

$G_{t}^{f} \quad$ is the average over Ages $a=0-A$ of the fishing mortality exerted by fleet $f$ in year $t$, with $\bar{G} f$ its average value over all years $t$,

$\varepsilon_{t}^{f} \quad$ is the year-effect of fishing mortality exerted by fleet $f$ (note that effective effort fluctuates in fidelity to the total catch each year),

$\gamma_{t, a}^{f}$ reflects the amount of change (over time period $b$ ) in the age effect of fishing by fleet $f$ for Age $a$, and

$b \quad$ is the period length (years) over which the age effect of fishing is constant.

The fishery is modelled as two "fleets": the Japanese longline fishery in Areas 3-9 $(f=1)$ and the combination of all other operations $(f=2)$. The reason for this split is that the first of these fleets has operated in a relatively consistent manner over time, whereas the second, which includes the variable Australian surface fishery component, has shown marked changes. This can be taken into account in the formulation by specifying lower input (or "prior") variances - $\left(G f_{\sigma_{G}}^{f}\right)^{2}$, $\left(\sigma_{H_{t}}^{f}\right)^{2}$ - for fleet $f=1$ than for $f=2$.

The stochastic error terms, $\varepsilon_{t}^{f}$ and $\gamma_{t a}^{f}$ are treated as free parameters subject to the constraints of their respective input variances: $\left(\bar{G} f_{\sigma_{G}^{f}}^{f}\right)^{2}$ and $\left(\sigma_{H_{t}}^{f}\right)^{2}$. If the age effects of fishing $\left(H_{t, a}^{f}\right)$ are constant over time, this results in a decomposition of the fleet-specific fishing mortality rate into an age component and a year component. This assumption creates what is known as a separable model (one example of which is CAGEAN; Deriso et al. 1985). If the age effect of fishing in fact changes over time, then the separable model can mask important changes in fish abundance. In these analyses, constraints are imposed through the variance term $\left(\sigma_{H_{t}}^{f}\right)^{2}$ that allows selectivity to change only slowly over time - thus improving ability to estimate the $\gamma_{t, a}^{f}$ s. The choice of the period $b$ over which $g$ is kept constant essentially involves a bias-variance trade-off: for $b$ too small, the model is over-parameterized, the data having insufficient information content to estimate all selectivity-related parameters with reasonable precision. However, choosing $b$ too large may not permit adequate flexibility for the model to represent possible real changes in the selectivity-at-age pattern over time. Furthermore, to provide smoothness in the age component, a curvature penalty $\left(\sigma_{H_{t}}^{f}\right)^{2}$ is placed on the age-specific coefficients using squared third-differences, i.e. the following term is added to the negative log-likelihood function for each fleet:

$$
\begin{aligned}
& \sum_{t=1}^{T} \sum_{a=0}^{A-3} \frac{\left(\ell \mathrm{n} H_{t, a+3}^{f}-3 \ell \mathrm{n} H_{t, a+2}^{f}+3 \ell \mathrm{n} H_{t, a+1}^{f}-\ell \mathrm{n} H_{t, a}^{f}\right)^{2}}{2\left(\sigma_{H_{a}}^{f}\right)^{2}} \\
& \quad=g f\left(H_{t, a}^{f} ;\left(\sigma_{H_{a}}^{f}\right)^{2}\right)
\end{aligned}
$$

This prevents irregular shifts between adjacent ageclasses. The reason for the choice of third-differences is that the data indicate $H$ to be dome-shaped with Age $a$ for most years, so selecting either first-differences (which penalizes all but independence in $a$ ), or seconddifferences (which favours linear behaviour with $a$ ) would be inappropriate.

A simple random walk is selected for the time-series effect on both $H_{t, a}^{f}$. Gudmundsson (1994) first introduced time-series structure in catchability and selectivity for analyses of catch-at-age data. Given the likely low information content of the catch-at-age information at the larger ages, the age-effects for each fleet are taken to be constant for Ages 17 and above, i.e. $\gamma_{t, a}^{f}=\gamma_{t, 17}^{f}$ for $a \geq 18$. Here the choice has been made to model fishing mortalities primarily as functions of the estimates of total removals (in contrast to modelling the fishery catchability and effort explicitly). This is considered reasonable in this case because estimates of total catch numbers are typically more reliable than measures of effort. As described below, total catch by number represents an important component of the likelihood function in providing estimates of the annual fishing mortality components. Furthermore, $G_{t}^{f}$ was modelled 
as a set of random deviates from a mean rather than as a random walk. This is because management actions have led to quite sharp changes in average fishing mortalities at certain times in the fishery, unlike the smoother pattern of changes that the random walk model suggests. The associated variance of $G_{t}^{f}$ is set quite high for the computations that follow, in contrast to the low variance input for annual catch number estimates, so the estimated $\varepsilon_{t}^{f}$ values are effectively determined by their need to reflect the input numbers caught very closely.

Note that the term $G_{t}^{f}$ represents the average rate of fishing mortality over all age-classes, because the $H_{t, a}^{f}$ term has a mean value of 1.0 over all ages for any given year. This framework for modelling the age-dependence of the fishing mortality components is similar to the " $F$ continuity" constraint used in past CCSBT SC assessments. In fact, Tsuji and Takeuchi (1997) used a second-differencing penalty directly on their estimates of $F$ s by age for each year. Additionally, this formulation can be readily adapted to model effective fishing effort through errors-in-variables, as presented elsewhere (e.g. Schnute 1994).

Recruitment $\left(R_{t}\right)$ represents numbers of Age- 0 fish and is modelled as an AR(1) stochastic process about a Beverton-Holt stock-recruitment relationship (as customarily assumed by the CCSBT SC):

$$
\left.\begin{array}{l}
N_{t, 0}=\tilde{R}_{t}=\frac{\alpha B_{t}^{s p} \mathrm{e}^{\tau_{t}-\sigma_{R}^{2} / 2}}{\beta+B_{t}^{s p}} \times \\
\tau_{t}=\rho \tau_{t-1}+\sqrt{1-\rho^{2}} \omega_{t}
\end{array}\right\}
$$

where $\rho$ is the serial correlation in the recruitment residuals, $\omega_{t} \sim N\left(0, \sigma_{R}^{2}\right)$, and $\tau_{t}$ has mean 0 and variance $\sigma_{R}^{2}$. The recruitment residuals $\left(\tau_{t}\right)$ are estimated also for 20 years prior to the onset of fishing, so as to allow the 1951 population age distribution to differ from that for pre-exploitation equilibrium to the extent that the data suggest. Effectively, therefore, the analyses provide population trend estimates from an assumed deterministic equilibrium situation in 1931, rather than 1951. Equation 5 can be reparameterized with $\alpha$ and $\beta$ replaced by the average pre-exploitation recruitment $R_{0}$ and the steepness parameter $h$. The exact relationship between these parameters is:

$$
\begin{aligned}
& \alpha=\frac{4 h R_{0}}{5 h-1} \\
& \beta=\frac{B_{0}^{s p}(1-h)}{5 h-1},
\end{aligned}
$$

where $\mathrm{B}_{0}^{s p}$ is the pristine mature (spawning) biomass corresponding to recruitment $R_{0}$ (these two quantities being related in terms of the mass-, fecundity- and natural mortality-at-age schedules).

Mature (spawning) biomass for year $t$ is defined as:

$$
B_{t}^{s p}=\sum_{a=8}^{30+} w_{t, a} N_{t, a}
$$

where choice of knife-edge age-at-maturity of $a=8$ years reflects a standard Reference case choice for past assessments conducted in the CCSBT SC (though there is now some debate in that body as to whether a higher value might be more appropriate). As the information on $w_{t, a}$ in Polacheck et al. (1997b) goes no further than Age 20, the body weight of older fish has been assumed to be the same as those aged 20 .

\section{Parameter estimation}

The likelihood components include data from the fishery catch-at-age composition estimates for each of the two "fleets" considered, the Japanese longline cpue for various age-groupings, the age distribution estimate for spawning biomass in 1994/95 and 1995/96, five years of aerial survey indices for the abundance of 3-yearold fish, and recent tag-recapture data. The objective function is simply the sum of the negative logarithms of the likelihood function components. The multinomial distribution is used to model the likelihood components for the age distribution data. Under this assumption, the log-likelihood function for the fishery catch-at-age data (in numbers) can be written:

$$
n^{f} \sum_{t, a} p_{t, a}^{f} \ell \mathrm{n}\left(\hat{p}_{t, a}^{f}\right)
$$

where

$$
p_{t, a}^{f}=\frac{O_{t, a}^{f}}{\sum_{a} O_{t, a}^{f}}, \quad \hat{p}_{t, a}^{f}=\frac{\hat{C}_{t, a}^{f}}{\sum_{a} \hat{C}_{t, a}^{f}},
$$

where $n f$ is the effective annual sample size and $O_{t, a}^{f}$, $\hat{C}_{t, a}^{f}$ represent the observed and predicted numbers-atage in the catch of fleet $f$ respectively. Effective sample size values are fixed at 60 for the longline fleet and 30 for the balance for the Reference case, because the former is considered to be better sampled. A similar term is used for the 1994/95-1995/96 age-distribution estimate of spawners, with an assumed effective sample size of 30. If every fish aged constituted an independent sample from the population concerned, actual sample sizes could be used. The need for effective sample sizes 
arises because the actual data are typically strongly correlated, because the samples are not independent and so carry much less information than is implied by assumptions of randomness. To compensate for this, effective sample sizes lower than actual sample sizes need to be used.

It is, however, clear from the data in Gunn et al. (1996) that the younger fish in the spawning population (given the standard Reference case assumption of 8 years as the age-of-maturity) are under-represented in this sample from the Indonesian longline fishery. This interpretation of under-representation is implicit in recent CCSBT SC assessments, and so has also been adopted for these analyses. (It should, however, be noted that Gunn et al. [1996] also offer and discuss alternative interpretations, including that the Reference case assumption of 8 years as the age at first maturity is too low.) The predicted age distribution is therefore not taken to be identical to the average of the numbers-at-age at the start of the years concerned, i.e. $0.5\left(N_{1995, a}+N_{1996, a}\right)$, but rather to these numbers modified by a selectivity function $\left(H_{a}^{s p}\right)$ :

$$
H_{a}^{s p}=\frac{1}{1+\mathrm{e}^{-\left(a-\theta_{1}\right) / \theta_{2}}},
$$

where the logistic function parameters $\theta_{1}$ and $\theta_{2}$ are estimated in the overall model-fitting process.

All series of abundance indices are treated as lognormally distributed about their expected values, i.e. having a negative log-likelihood which can be written

$$
\phi^{c} \sum_{t}\left[\ell \mathrm{n}\left(I_{t}^{c} / \hat{I}_{t}^{c}\right)\right]^{2},
$$

where

$$
\begin{aligned}
& \hat{I}_{t}^{c}=q_{t}^{c} X_{t}^{c} \\
& q_{t+1}^{c}=q_{t}^{c} \mathrm{e}^{\delta_{t},} \quad \delta_{t} \sim N\left(0 ; \sigma_{\delta}^{2}\right),
\end{aligned}
$$

where $\phi^{c}$ represents assumptions made about the variance of the abundance indices (with a separate value for each index type $c$ ) and $X_{t}^{c}$ is the model prediction of the quantity that the index is assumed to reflect. Therefore, for the aerial survey, $x_{t}^{c}=N_{t, 3}$ the predicted number of 3-year-olds in the population at the start of year $t$. The specification of $x_{t}^{c}$ for the longline cpue indices, which relate to fleet $f=1$, is somewhat more complicated, even given that, for the Reference case, the general assumption of no time dependence in the catchability coefficients $q_{t}^{c}$ is made (i.e. $\delta_{t}=0$ or equivalently $\sigma_{\delta}=0$ ). The reason is that the age-effect term for the fleet concerned
$\left(H_{t, a}^{1}\right)$ does show some time-dependence, so some agespecific catchabilities are changing over time. To remove confounding in the cpue v. abundance relationship then, it is necessary to specify some reference age (or group of ages) for which the catchability is assumed to be time-invariant. Age 8 was chosen because this seems usually to be the age most highly selected by the Japanese longliners. Therefore, the quantity reflected by a cpue index for an age-group from Age $a_{1}$ to $a_{2}$ is defined as:

$$
X_{t}^{c}=\sum_{a=a_{1}}^{a_{2}} \frac{H_{t, a}^{1} N_{t, a}}{H_{t, 8}^{1}},
$$

where the average taken of numbers-at-age $N$ is to reflect that cpue provides an index of average abundance over the year.

Tag-recapture data have been incorporated in the manner suggested by Polacheck et al. (1997b), contributing the following term to the negative log-likelihood:

$$
\sum_{t, a} \frac{\left\{\sqrt{r_{t, a}}-\sqrt{\hat{r}_{t, a}}\right\}^{2}}{2 \sigma_{\text {tag }}^{2}},
$$

where $r_{t, a}$ is the number of tag returns of Age $a$ in year $t$ that have been at liberty for more than one year.

If the tag-recapture process is governed by a Poisson distribution, the square-root transformation of Equation 12 should produce variables approximately normally distributed with a standard deviation $\sigma_{t a g}=0.5$. In practice, some overdispersion would be expected, so $\sigma_{t a g}$ was set to 2.0 for the Reference case.

The expected number of returns $\left(\hat{r}_{t, a}\right)$ of Age $a$ recovered in year $t$ is given by (Polacheck et al. 1997b):

$\hat{r}_{t, a}=\lambda_{t, a} \sum_{k=1}^{a-1} R_{t-k, a-k} \mathrm{e}^{-\left(M_{a-k}+F_{t-k, a-k}^{*}\right)} \times$

$\left[\prod_{j=1, k>2}^{k-1} \mathrm{e}^{-\left(M_{a-j}+F_{t-j, a-j}\right)} \frac{F_{t, a}}{M_{a}+F_{t, a}}\left\{1-\mathrm{e}^{-\left(M_{a}+F_{t, a}\right)}\right\}\right]$

where

$R_{t-k, a-k}$ is the number of tags released in year $t-k$ on fish of Age $a-k$,

$F_{t, a} ; M_{a}$ are the fishing and natural mortality rates, as for Equation 1,

$\lambda_{\mathrm{t}, a}$ is the tag-reporting rate for fish of Age $a$ in year $t$, and

$F_{t-k, a-k}^{*}$ is the fishing mortality rate for tagged fish during their first year of liberty (which may differ from $F_{t-k, a-k}$ because of incomplete 
mixing of tagged fish with the rest of the population during this period).

$F_{t-k, a-k}^{*}$ is estimated from the number of tags recovered during their first year of liberty by use of the catch equation:

$$
\begin{aligned}
r_{t-k, a-k}^{*}= & \lambda_{t-k, a-k} R_{t-k, a-k} \frac{F_{t-k, a-k}^{*}}{M_{a-k}+F_{t-k, a-k}^{*}} \times \\
& \left(1-\mathrm{e}^{-\left(M_{a-k}+F_{t-k, a-k}^{*}\right)}\right),
\end{aligned}
$$

where $r_{t-k, a-k}^{*}$ is the number of returns of tags from fish of Age $a-k$ in the same year $(t-k)$ as they were released.

The Reference case computations of this paper use reporting rate model number 5 of Polacheck et al. (1998) for the values. This model is intermediate within the range of eight models for reporting rate which those authors consider.

The contribution of models for $G, H$ and $q$ to the negative log-likelihood function is:

$$
\begin{gathered}
\phi_{\varepsilon}^{f} \sum_{f, t}\left(\varepsilon_{t}^{f}\right)^{2}+\phi_{\gamma}^{f} \sum_{f, t, a}\left(\gamma_{t, a}^{f}\right)^{2} \\
+\sum_{f} g f\left(H_{t, a}^{f} ;\left(\sigma_{H_{a}}^{f}\right)^{2}\right)+\phi_{\delta} \sum_{t} \delta_{t}^{2},
\end{gathered}
$$

where the sizes of the $\phi$ s represent input assumptions about the variances of these random variables. For example,

$$
\phi_{\varepsilon}=\frac{1}{2\left(\bar{G}^{f} \sigma_{G}^{f}\right)^{2}}, \quad \phi_{\gamma}=\frac{1}{2\left(\sigma_{H_{t}}^{f}\right)^{2}}, \phi_{\delta}=\frac{1}{2 \sigma_{\delta}^{2}} .
$$

For readers unfamiliar with this approach, it is useful to consider what values some of these variance terms would be under "traditional" stock assessment models. For example, because VPA models assume that catchesat-age are known exactly, all error is typically absorbed by the year-age-specific fishing mortality rates. This implies that the variance terms $\left(\sigma_{H_{f}}^{f}\right)^{2}$ and $\left(\sigma_{H}^{f}\right)^{2}$ are effectively infinite in magnitude. In other age-structured models that make the separability assumption (described above) and have constant selectivity over time, these variance terms are effectively zero. The approach taken here provides some moderation between these extremes.

Finally, a penalty function for the steepness parameter $h$, essentially equivalent to a Bayesian prior for this quantity, is added to the negative log-likelihood. From inspection of such priors for four species groups given in Appendix III of Hilborn et al. (1998), this penalty was chosen as the log of a normal distribution with mean of 0.85 and standard deviation of 0.25 .

For all but one model presented below, more than 500 parameters were estimated. Most of these parameters are associated with year-to-year and age-specific deviations in selectivity (age-effect) coefficients. Schnute (1994) presents a broad discussion of this type of approach to modelling errors-in-variables. To estimate such a large number of parameters in a nonlinear model easily, automatic differentiation software extended from Greiwank and Corliss (1991) and developed into $\mathrm{C}++$ class libraries was used. This software provided the derivative calculations needed for finding the likelihood mode via a quasi-Newton function minimization routine (e.g. Press et al. 1992). The model implementation language (AD Model Builder) gave simple and rapid access to these routines and provided the ability to estimate the variancecovariance matrix for all dependent and independent parameters of interest. For key quantities of interest, e.g. current abundance, the software can also produce likelihood profiles and marginal posterior probability densities (using the MCMC algorithm; Gelman et al. 1995), both of which avoid the assumption that the likelihood shape is quadratic (implied when the inverse Hessian estimates are used).

The number of parameters estimated for this model depend in large part on the parameter $b$, the value of which governs the frequency of change in selectivity over time. Initial runs with different values of $b$ suggested that $b=4$ gave results similar to the higher dimensional problem, while higher values seemed unduly restrictive. Years for which $H$ changed were chosen such that the last four years of the analysis (1994-1997) formed one such four-year block. Also, $H$ was assumed invariant over the period 1951-1965 given the paucity of age data for those years. Other parameters estimated were:

1. the $q$ values for each abundance index (furthermore, time-trend deviations $\left(\delta_{t}\right)$ would be included in any sensitivity tests that do not fix $q$ to be constant);

2. the Beverton-Holt stock-recruitment function parameters $h$ and $R_{0}$ (a reparameterization of $\alpha$ and $\beta$ ) - see Equation 5;

3. the recruitment in each year since 1951 and the residuals of the first 20 ages in the age distribution in 1951 relative to equilibrium;

4. the age-effect deviations $\gamma_{t, a}^{f}$ for the two fleets considered;

5. the annual variation in fishing mortality in each year reflected by $\varepsilon_{t}^{f}$ for the two fleets considered; and

6. the logistic selectivity function parameters $\theta_{1}$ and $\theta_{2}$ used in fitting to the Gunn et al. (1996) spawner age-distribution data. 
The complete objective function upon which the estimation is based has the following component (negative log-) likelihood parts:

$$
\begin{aligned}
-\ell \mathrm{n} L_{1} & =\sum_{c} \sum_{t} \frac{\left[\ell \mathrm{n}\left(I_{t}^{c} / \hat{I}_{t}^{c}\right)\right]^{2}}{2\left(\sigma^{c}\right)^{2}}, \\
c & =\left\{\begin{array}{l}
\text { Aerial survey } \\
C p u e \text { indices } \\
\text { Total catch numbers } \\
\text { Stock - recruitment relationship }
\end{array}\right\} \\
-\ell \mathrm{n} L_{2} & =-\sum_{d} n^{d} \sum_{t, a} p_{t, a} \ell \mathrm{n}\left(\hat{p}_{t, a}\right) \\
d & =\left\{\begin{array}{l}
\text { Catch }- \text { age data by fleet } \\
\text { Age }- \text { distribution on spawning ground }
\end{array}\right\} \\
-\ell \mathrm{n} L_{3} & =\phi_{\varepsilon}^{f} \sum_{t}\left(\varepsilon_{t}^{f}\right)^{2}+\phi_{\gamma}^{f} \sum_{f, t, a}\left(\gamma_{t, a}^{f}\right)^{2} \\
& +\sum_{f} g f\left(H_{t, a}^{f} ;\left(\sigma_{H_{a}}^{f}\right)^{2}\right)+\phi_{\delta} \sum_{t} \delta_{\mathrm{t}}^{2} \\
-\ell \mathrm{n} L_{t o t} & =\sum_{i=1}^{5}-\ell \mathrm{n} L_{i} \cdot . \\
-\ell n L_{5} & =\frac{(h-0.85)^{2}}{2(0.25)^{2}} \\
& =\sum_{t, a} \frac{\left(\sqrt{r_{t, a}}-\sqrt{\hat{r}_{t, a}}\right)^{2}}{2 \sigma_{t a g}^{2}}
\end{aligned}
$$

Strictly, the stock-recruitment relationship contribution to $L_{1}$ has the form indicated only in the case where serial correlation $\rho=0$ (see Equation 5). When $\rho$ is non-zero, the numerator indicated is replaced by $\left(\omega_{t}\right)^{2}$. Why take account of this relationship at all in the fitting? Reasons that apply generally are to facilitate estimation of otherwise poorly determined recent recruitment levels in the assessment, and to ensure self-consistency: some stock-recruitment relationship will be required to perform stock projections for manage- ment advice, so it is presumably best to use one whose estimation is consistent with the assessment itself. However, in the SBT case there is the further reason that, even after downweighting the contribution of the stock-recruitment relationship term through account being taken of the serial correlation of the residuals, this term remains one of the most influential in the likelihood when estimating the value of the steepness parameter $h$, and hence of the resource's productivity level.

\section{Reference case specifications and ADAPT analogue}

There are a number of choices to be made for input data and parameter values for a Reference case application of the method described above. Generally, the selections made have, where pertinent, attempted to choose near the centre of ranges of options that have been argued in the CCSBT SC.

1. Cриe series: geostatistical.

2. Natural mortality-at-age: vector "V6" of those considered by the 1998 CCSBT SC meeting (see Table I). The multi-year tag-return data (Polacheck et al. 1997c) do admit the possibility of estimating $M_{a}$ for Ages 1 and 2, but this has not been attempted in the fits of this paper because the standard errors for those estimates were relatively large, and the choices reflected in Table I for $M_{a}$ are broadly consistent with the estimates for $M_{1}$ and $M_{2}$ in Polacheck et al. (1997c).

3. Plus-group age: $A=30$.

4. Age-at-maturity: knife-edge at Age $a=8$.

5. Stock-recruitment relationship: Beverton-Holt.

6. Tag-reporting rate model: No. 5 of Polacheck et al. (1997c).

7. Variance related parameters (refer to Equation 15): (a) $\ell$ n $L_{1}: \sigma^{c}$

\begin{tabular}{|c|c|c|c|c|c|c|c|c|c|c|c|}
\hline \multirow{2}{*}{ Vector } & \multicolumn{11}{|c|}{ Age } \\
\hline & 0 & 1 & 2 & 3 & 4 & 5 & 6 & 7 & 8 & 9 & $10+$ \\
\hline
\end{tabular}

(i) aerial survey - from available data (Table 6.4 of Cowling and Millar 1998)

(ii) Сриe - maximum likelihood estimates from model fit, but restricted such that $\sigma^{c} \geq 0.1$ to avoid possible overweighting of these data relative to others

(iii) total catch numbers $-\sigma^{c}=0.05$

Table I: Schedules of natural mortality rates (per year) at age utilized in the assessments 
(iv) stock-recruitment relationship $-\sigma^{c}=\sigma_{R}$ $=0.4, \rho=0.8$ (see Results and Discussion (b) $\ell$ n $L_{2}: n^{d}$ section for the reasons for these choices).

(i) catch-at-age data by fleet $-n^{d}=60$ for $f=1$ and 30 for $f=2$

(ii) age distribution on spawning ground $n^{d}=30$.

(c) $\ell$ n $L_{3}$ :

(i) $\sigma_{F}^{f}=6.0$ for $f=1,2$

(ii) $\sigma_{H_{t}}^{f}=0.2$ for $f=1$ and 0.4 for $f=2$; and $b=4$

(iii) $\sigma_{H_{a}}^{f}=0.1$ for $f=1$ and 0.2 for $f=2$

(iv) $\sigma_{\delta}=0$ (i.e $q$ constant over time)

(d) $\ell$ n $L_{4}: \sigma_{\text {tag }}=2.0$

Note that the final set of selectivies $H_{t, a}^{2}$ for the other operations are treated as free parameters unrelated to earlier years because of change in regulations regarding the take of small fish over that period, so as to avoid, inter alia, artificially depressing estimates of recruitment for the past few years when these operations landed very few small fish. The $\sigma_{H_{a}}^{f}$ values are kept smaller for the longline than for the other operations because the former have been less subject to change over time. They are also deliberately low (compared with what the data suggest) with a view towards keeping the age dependence in selectivity patterns reasonably smooth.

To obtain an ADAPT analogue to this Reference case, where this analogue assumes error-free catch-at-age data taken only to Age 12+, the following modifications are made to the specifications in item 7 above:

(a) (i) total catch numbers are taken to be exact $\sigma^{c}=0$.

(b) (i) catch-at-age data by fleet $-n^{d} \rightarrow \infty$ for both $f=1$ and $f=2$, but the observed and predicted age compositions are aggregated for Ages 12+;

(ii) age distribution on spawning ground - omitted (restriction to Ages $\leq 12$ years precludes use of these data).

(c) (i) no constraint on year-effect variation in $F$ $\sigma_{G}^{f} \rightarrow \infty$ for $f=1,2$;

(ii) no constraint on age-effect variation in $F-$ $\sigma_{H_{t}}^{f} \rightarrow \infty$ for $f=1,2$; and $b=1$.

\section{RESULTS AND DISCUSSION}

As will become evident from the results that follow, the key parameter in assessing the productivity, and hence recovery prospects, of the SBT resource is the steepness $h$. In estimating $h$, an important consideration is the contribution made to the overall (negative log-) likelihood by the residuals about the stock recruitment relation of Equation 5, through Equation 14 for

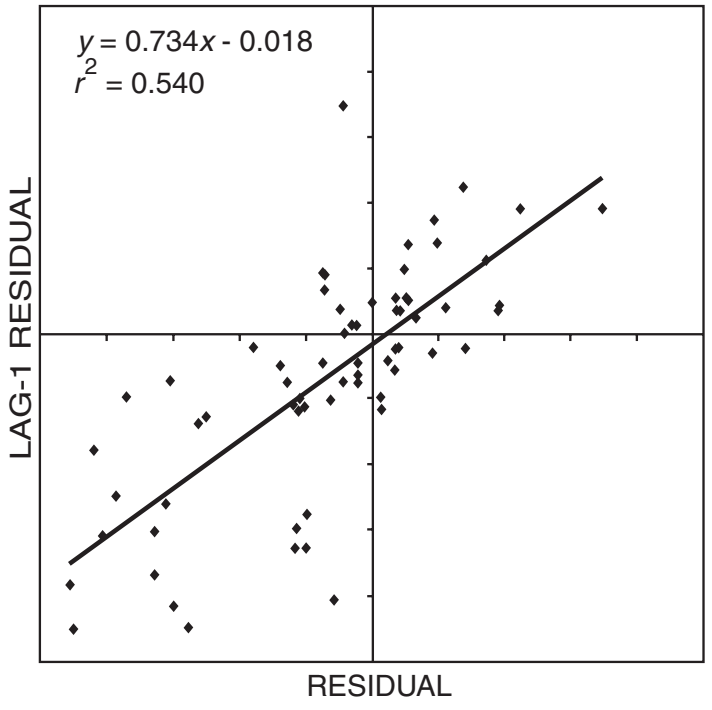

Fig. 3: Stock-recruitment lag-1 residuals v. stock-recruitment residuals for the Reference case without serial correlation specified in stock-recruitment model (i.e. $\rho=0$ )

- $\ell$ n $L_{1}$. This in turn depends on the values input for the standard deviation $\left(\sigma_{R}\right)$ and serial correlation $(\rho)$ of these residuals; in both respects, larger values mean a less influential contribution to the likelihood.

A value of $\sigma_{R}=0.4$ was selected, being perhaps a little on the low side of that typical for pelagic fish populations. Figure 3 shows the stock-recruitment residuals for a fit of the Reference case with $\rho=0$ input, plotted against themselves with a lag of one year. High positive serial correlation is evident, with the estimates manifesting an "output" $\rho$ of 0.77 . For all following computations, $\rho$ was fixed at the rounded value of 0.80 . Results given in Tables II and III show "output" values of $\sigma_{R}$ and $\rho$ (i.e. estimates implied by the residuals about the fitted model), which are consistently somewhat higher than these input choices of 0.4 and 0.8 respectively. Therefore, the contribution of the stock-recruitment residuals is still likely overweighted somewhat in fitting the model, though not to the extent that would have been the case were the serial correlation ignored by setting the "input" $\rho$ to zero. Sensitivity analyses yielded similar results if earlier residuals (up to the mid-1960s) were ignored in such computations, and also showed little if any correlation remaining after the one-year-lag effect had been taken into account in terms of Equation 5. It should, however, be noted that apparent positive serial correlation will have been enhanced, to some extent, by the "smearing" associated with ageing errors: for example, inaccurate estimation of the ages of fish 
Table II: Summary results of Reference case model compared with those for alternative values of steepness $h$. Note that the negative log-likelihood values are shown relative to the minimum value for different steepness cases, and that the penalty term corresponding to the prior on steepness $h$ is excluded from the log-likelihood for these computations

\begin{tabular}{|c|c|c|c|c|c|c|c|c|c|}
\hline Parameter & 0.2 & 0.3 & 0.4 & 0.5 & 0.6 & 0.7 & 0.8 & 0.9 & 1.0 \\
\hline \multicolumn{10}{|c|}{-ln Likelihood } \\
\hline Aerial index & 0.77 & 0.52 & 0.33 & 0.19 & 0.11 & 0.04 & 0.01 & 0.00 & 0.01 \\
\hline Overall cpue index & 0.00 & 0.69 & 1.30 & 1.73 & 2.00 & 2.16 & 2.26 & 2.31 & 2.33 \\
\hline Total catch numbers & 0.00 & 0.05 & 0.10 & 0.14 & 0.18 & 0.20 & 0.22 & 0.22 & 0.22 \\
\hline Fit to longline age composition & 1.59 & 1.18 & 0.88 & 0.66 & 0.49 & 0.33 & 0.18 & 0.08 & 0.00 \\
\hline Fit to $1995-1996$ spawner age distribution & 1.29 & 0.99 & 0.66 & 0.40 & 0.22 & 0.12 & 0.06 & 0.02 & 0.00 \\
\hline$F$ penalty & 0.03 & 0.02 & 0.01 & 0.01 & 0.00 & 0.00 & 0.00 & 0.00 & 0.00 \\
\hline Sigma $H_{t}$ balance & 0.49 & 0.28 & 0.14 & 0.04 & 0.00 & 0.01 & 0.05 & 0.08 & 0.11 \\
\hline Sigma $H_{t}$ longline & 0.00 & 0.04 & 0.12 & 0.24 & 0.37 & 0.49 & 0.55 & 0.54 & 0.50 \\
\hline Age-effect balance & 0.61 & 0.50 & 0.35 & 0.22 & 0.12 & 0.05 & 0.01 & 0.00 & 0.00 \\
\hline Age-effect longline & 0.00 & 0.32 & 0.45 & 0.49 & 0.49 & 0.46 & 0.43 & 0.42 & 0.42 \\
\hline
\end{tabular}

Root mean square error $=\sqrt{\sum[\ell n(\text { obs } / \text { pred })]^{2} / n^{*}}$

Age $4(>0.1)$

Age $5(>0.1)$

Ages 6 and $7(>0.1)$

Ages $8-11(>0.1)$

Ages $12+(>0.1)$

Catch numbers longline $(0.05)$

Catch numbers balance (0.05)

Effective $n{ }^{\dagger}$ 1994/5-1995/6 spawning age

distribution (30)

Effective $n$ longline (60)

Effective $n$ balance (30)

Selectivity curvature balance $(0.40)$

Selectivity curvature longline $(0.20)$

Balance Sigma $H_{t}(0.20)$

Longline Sigma $H_{t}(0.20)$

Aerial survey Age 3

Tag $S D(2.0)$

$\rho$ estimate $(0.8)$

Recruitment variability $(0.40)$

Sigma $F\left(G_{t}\right)$ balance (6.0)

Sigma $F\left(G_{t}\right)$ longline (6.0)

\begin{tabular}{|c|c|c|c|c|c|c|c|c|c|}
\hline $1951 / B_{0}^{s p}$ spawner ratio & 1.21 & 0.94 & 0.87 & 0.83 & 0.80 & 0.79 & 0.79 & 0.80 & 0.81 \\
\hline $1980 / B_{0}^{s p}$ spawner ratio & 0.81 & 0.58 & 0.50 & 0.46 & 0.43 & 0.42 & 0.43 & 0.44 & 0.46 \\
\hline $\begin{array}{l}\text { 1997/1951 spawner ratio } \\
(C V) \\
1997 / 1980 \text { spawner ratio } \\
1997 / 1995 \text { spawner ratio } \\
1997 \text { spawner biomass (thousand tons) } \\
(C V)\end{array}$ & $\begin{array}{l}0.29 \\
(23 \%) \\
0.43 \\
0.96 \\
248 \\
(25 \%)\end{array}$ & $\begin{array}{l}0.26 \\
(23 \%) \\
0.43 \\
0.98 \\
191 \\
(29 \%)\end{array}$ & $\begin{array}{l}0.25 \\
(25 \%) \\
0.43 \\
1.01 \\
150 \\
(32 \%)\end{array}$ & $\begin{array}{l}0.23 \\
(27 \%) \\
0.42 \\
1.03 \\
122 \\
(35 \%)\end{array}$ & $\begin{array}{l}0.22 \\
(28 \%) \\
0.41 \\
1.06 \\
104 \\
(36 \%)\end{array}$ & $\begin{array}{c}0.22 \\
(28 \% \\
0.41 \\
1.08 \\
94 \\
(36 \%)\end{array}$ & $\begin{array}{l}0.22 \\
(28 \%) \\
0.41 \\
1.09 \\
90 \\
(35 \%)\end{array}$ & $\begin{array}{c}0.23 \\
(28 \%) \\
0.42 \\
1.09 \\
90 \\
(36 \%)\end{array}$ & $\begin{array}{c}0.24 \\
(27 \%) \\
0.42 \\
1.09 \\
93 \\
(37 \%)\end{array}$ \\
\hline $\begin{array}{l}B_{0}^{s p} \text { (thousand tons) } \\
R_{0} \text { (millions) } \\
\text { Steepness }(h)\end{array}$ & $\begin{array}{c}709 \\
6542 \\
0.2\end{array}$ & $\begin{array}{c}773 \\
7132 \\
0.3\end{array}$ & $\begin{array}{c}699 \\
6447 \\
0.4\end{array}$ & $\begin{array}{c}633 \\
5840 \\
0.5\end{array}$ & $\begin{array}{c}582 \\
5373 \\
0.6\end{array}$ & $\begin{array}{r}543 \\
5009 \\
0.7\end{array}$ & $\begin{array}{r}512 \\
4720 \\
0.8\end{array}$ & $\begin{array}{c}487 \\
4495 \\
0.9\end{array}$ & $\begin{array}{r}470 \\
4332 \\
1.0\end{array}$ \\
\hline
\end{tabular}

* Input values assumed for the Reference case are shown in parenthesis

$\dagger$ This is simply the computation $\sum \hat{p}_{t, a}\left(1-\hat{p}_{t, a}\right) / \sum\left(p_{t, a}-\hat{p}_{t, a}\right)^{2}$ that gives an approximation to the effective sample size based on the model fit (for details, see McAllister and Ianelli 1997, Appendix 2) 
Table III: Reference case compared with implementations with alternative configurations and/or assumptions. The negative log-likelihood contributions are shown in absolute terms here, in contrast to practice in Table II

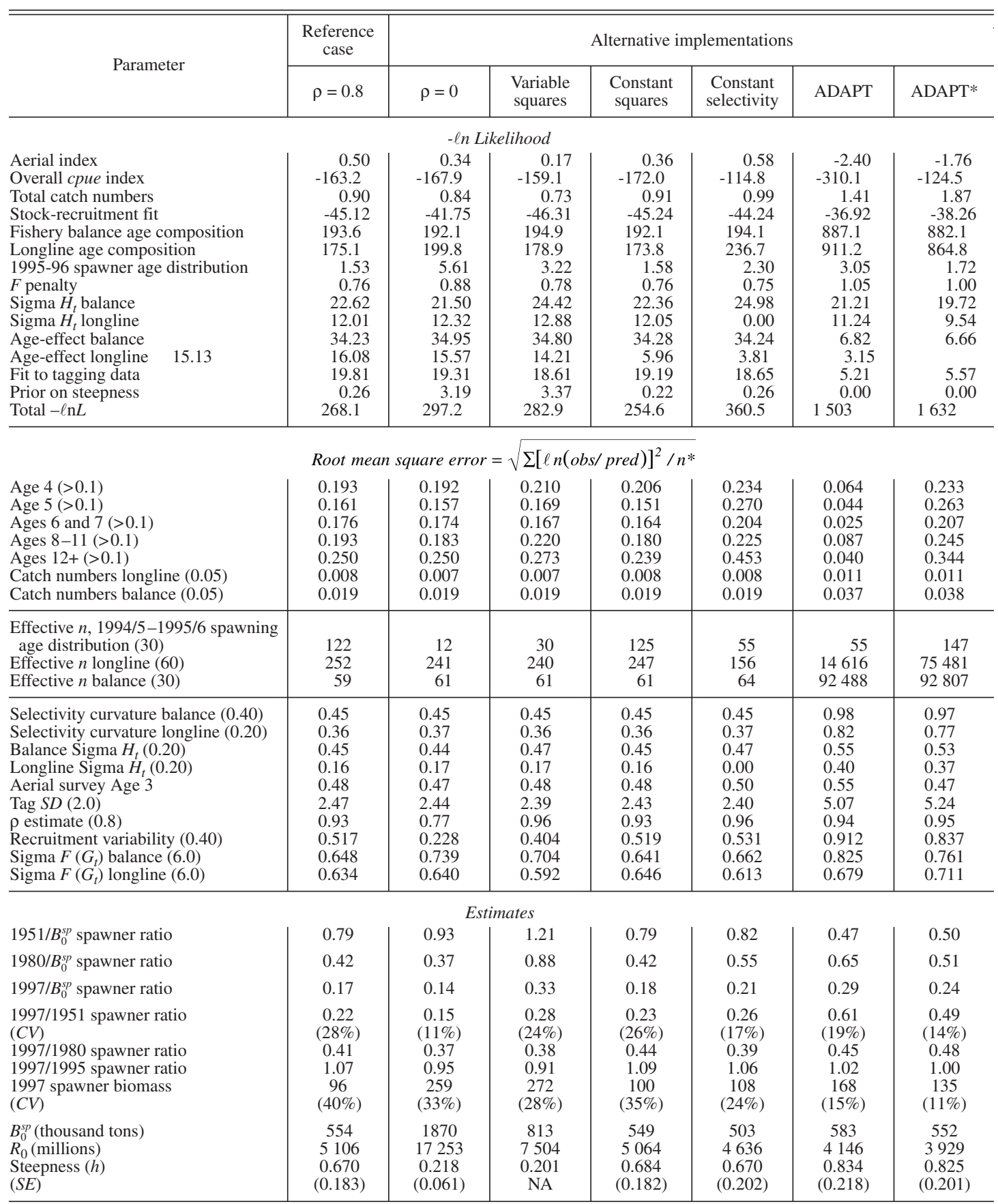



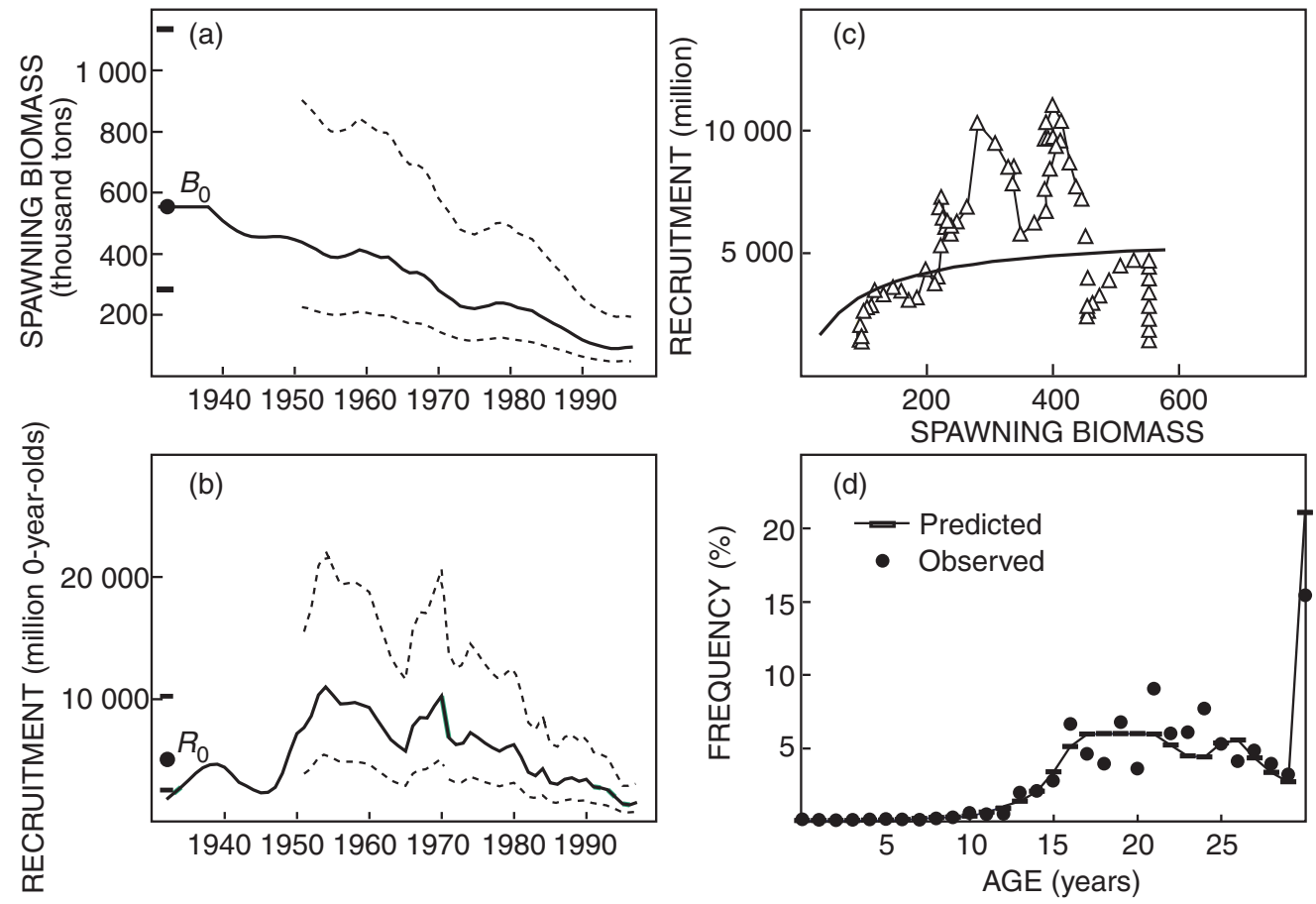

Fig. 4: Summary results for Reference case for (a) spawning biomass and (b) recruitment over time, and (c) stock-recruitment estimates and (d) observed and model prediction of 1994/95-1995/96 spawning ground age composition data (where the values plotted for Age 30 are for a plus group). Error bands represent $\pm 2 S E$ (of the logarithms) of the estimates. The curve added to the stock-recruitment plot (c) is the estimated relationship as per Equation 5. Here and in all tables and figures following, spawning biomass is reported in thousand tons, and recruitment is in millions (by number) of 0-year-olds

from an unusually strong cohort causes them to be incorrectly assigned to adjacent cohorts, so misleadingly suggesting that those cohorts are also somewhat stronger than normal.

The results of the fit of the Reference case for these input values of $\sigma_{R}$ and $\rho$ are shown in Figures 4-8, with the associated parameter estimates, log-likelihood contributions and "output" variance estimates listed in Table III. The estimate of $h$ for this Reference case is 0.67 . Standard error estimates are based on the inverse of the Hessian, coupled where necessary to application of the delta approximation.

The stock-recruitment plot in Figure 4 suggests that the history of the resource has been marked by periods of below-expected recruitment prior to the commencement of the fishery, above-expected recruitment over the 1950 s to the 1970 s, and then recruitment somewhat below-expected levels again in the 1980s and early 1990s. The high output value for the $\rho$ parameter in the model fit is a reflection of these periods of high and low recruitment, which might alternatively be described as "regime shifts", or as a manifestation of non-stationarity in population parameters (Sainsbury 1998). The recruitment estimates for the last four years 1994-1997 in these analyses should not be accorded high reliability because, apart from the stock-recruitment function, they are determined solely by a single datum: the aerial survey estimate for 3-year-olds in 1997. This last factor also means that the associated confidence intervals shown for recruitment for these years are negatively biased to some extent.

The Reference case fit in Figure 4 indicates a slight recovery in spawning biomass commencing in 1995. The Gunn et al. (1996) spawner age composition data appear reasonably fitted.

There are no obvious systematic deviations evident in the fits to the cрue, aerial survey and tag-recapture data shown in Figures 5 and 6. The cpue fits, however, must be considered in the context of the greater flexi- 

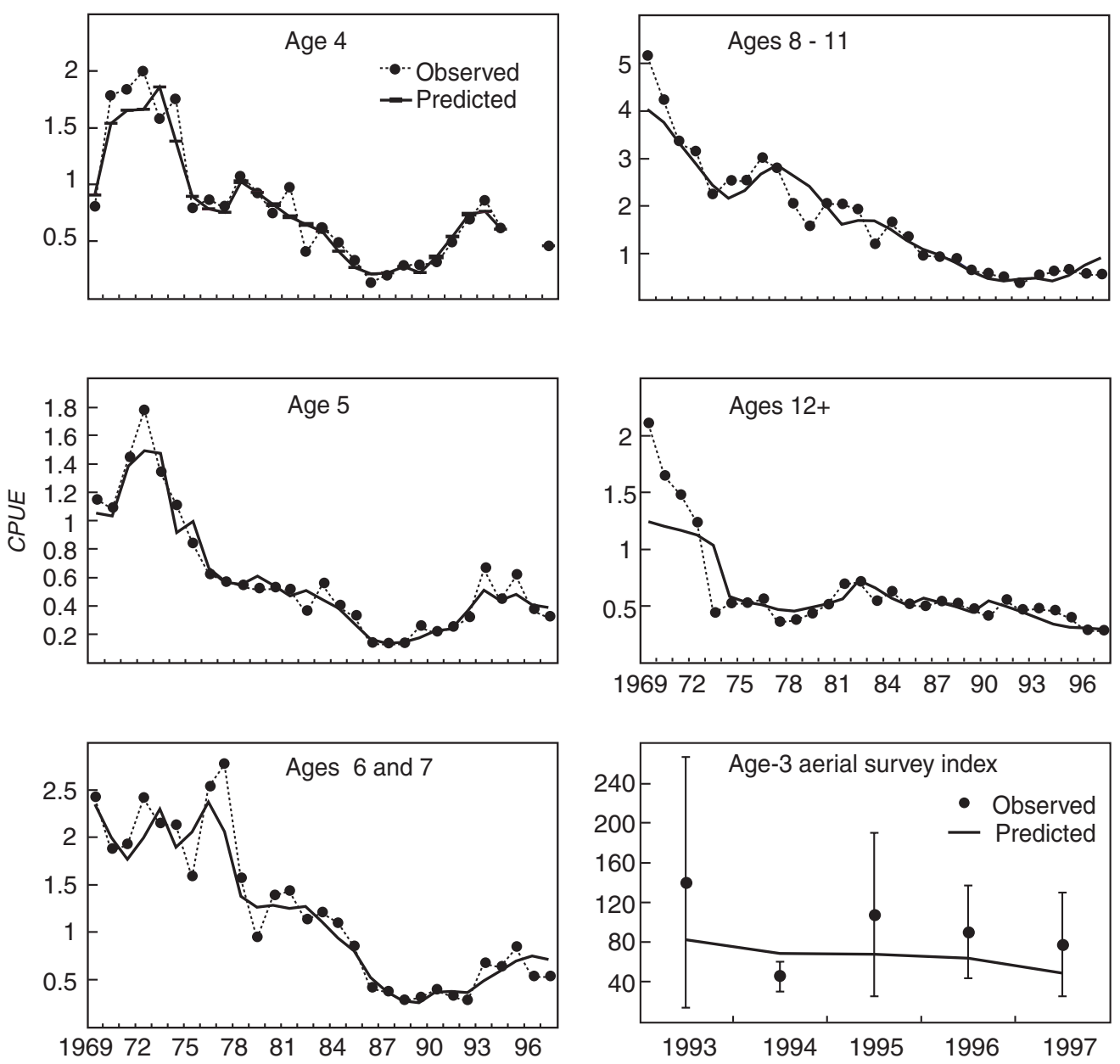

Fig. 5: Fits to index longline cpue (geostatistical) data and the Age-3 aerial survey index for the Reference case. Error bars for aerial survey index represent $\pm 2 S E$ from observed estimates

bility of this approach (compared with those used previously in the CCSBT SC) to fit longline cpue trends. This arises particularly because the possibility of temporal changes in selectivity patterns is now admitted. The estimates of these changing selectivity patterns are shown in Figure 7. Especially evident is the estimated steep decline in selectivity for tuna above about Age 10 for the longline gear as deployed in Areas 3-9. Because longline gear generally manifests enhanced selectivity for larger (older) fish, this decline is presumably a reflection in the main of an increasing tendency with age for the larger fish to be distributed in regions other than those normally fished, rather than primarily a gear effect. This adds weight to concerns about analyses that assume a fixed, time-invariant relationship between fishing mortalities on Ages 11 and $12+$ in the fishery. The selectivity patterns for the "fishery balance" show much more marked changes over time than those for the longliners; this follows, in particular, from the need to accommodate the growth of the Australian purse-seine fishery on young fish that commenced in the late 1960s.

An example of the fits to the catch-at-age data (for the Area 3-9 longline catches in this instance) is 

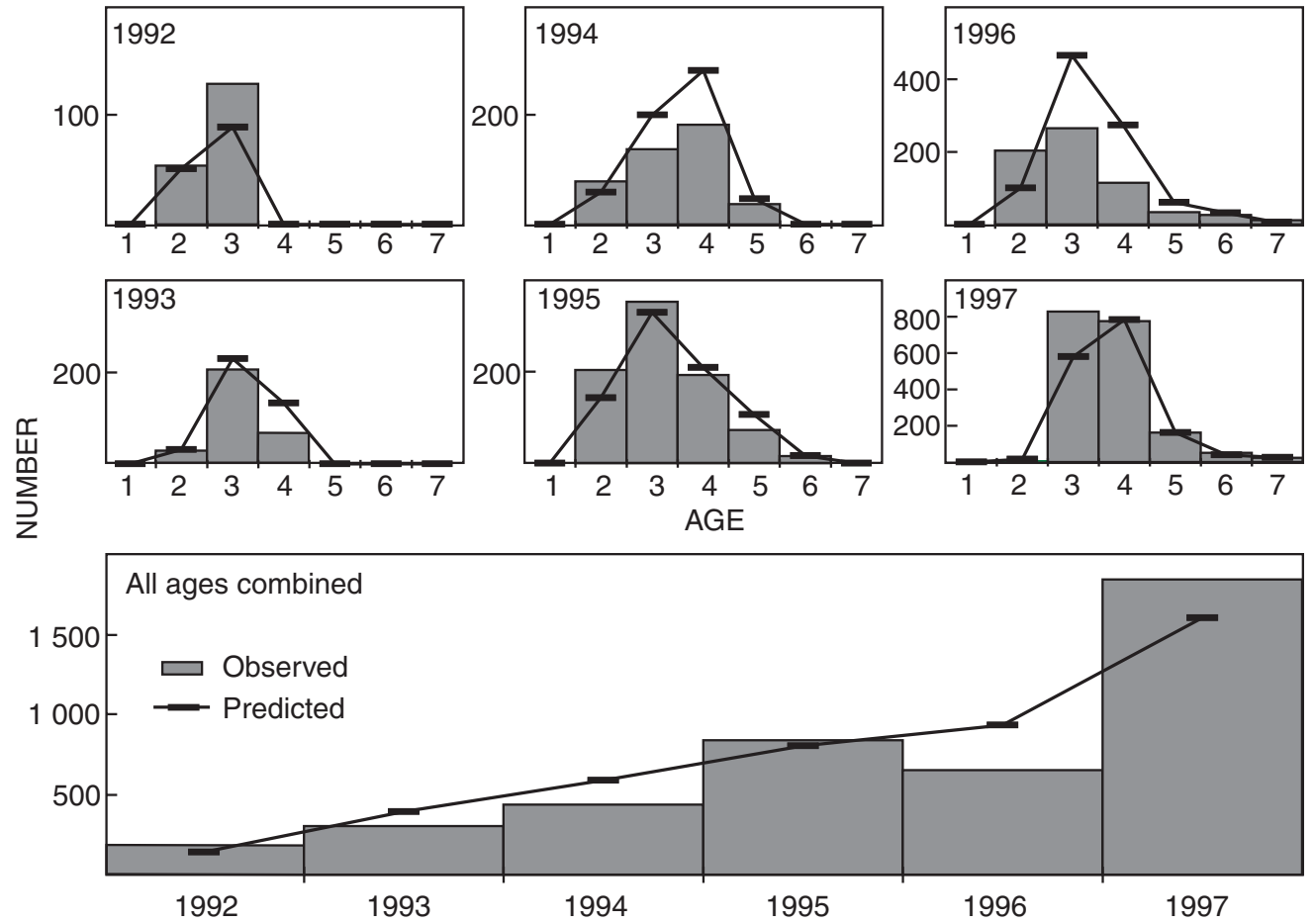

Fig. 6: Fit to age-specific tag-recapture data by number for Reference case by year. The bottom panel is shown for display purposes only - aggregated tag-recapture data were not used in the likelihood computations

shown in Figure 8. These fits are generally good, except for some years in the early 1950s, when sampling for such information was sparse.

\section{Estimation of the steepness parameter $h$}

Table II lists results for the fit of the Reference case when steepness $h$ is not estimated, but rather fixed upon input. The trends in contributions from each term in the negative log-likelihood as $h$ changes show how influential that information is in determining $h$ and hence resource productivity; generally, a change of more than about 2 is required for a statistically meaningful effect. Figure 9 includes a plot of the contributions to $-\ell \mathrm{n} L$ across the full range $h=0.2-1.0$ from all sources, but excluding the penalty associated with the steepness prior (- $\ell \mathrm{n} L_{5}-$ see Equation 15). Though favouring lower values of steepness, these contributions nevertheless reflect a change in this net contribution of only 1.82 across the complete range for steepness.
While admitting that this approach, given the nature of some of the penalty functions included in the overall likelihood, cannot be rigorously defended as entirely within a pure frequentist paradigm, it remains notable that, within that paradigm, a change in $-\ell \mathrm{n} L$ as small as this would be interpreted as an inability (at the $5 \%$ significance level) to draw any inference about the value of $h$ within its full range of $0.2-1.0$ from these data. This renders the incorporation of the steepness prior information (through the $-\ell \mathrm{n} L_{5}$ term) all the more necessary in this instance. This contribution and the net overall negative log-likelihood as a function of $h$, are also plotted in Figure 9.

In spite of this non-significant result, it remains of interest to consider in which direction the various contributions to $-\ell$ n $L$ tend to "push" the estimate of $h$. From inspection of Table II, it is evident that the сриe data, tagging data and the stock-recruitment fit itself favour lower values of $h$, whereas both sets of commercial catch-at-age data, the Gunn et al. (1996) spawner age data and the aerial survey data favour 
(a) Longline gear Areas 3-9

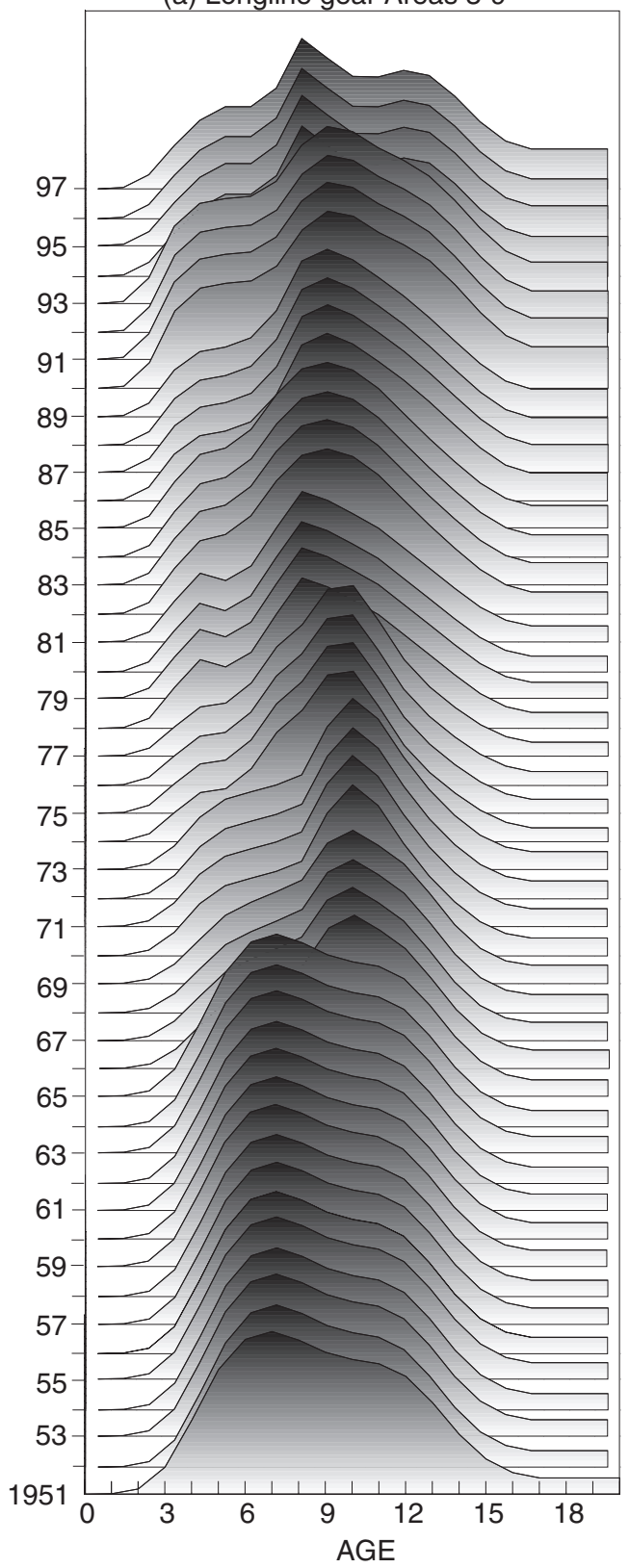

(b) Fishery balance

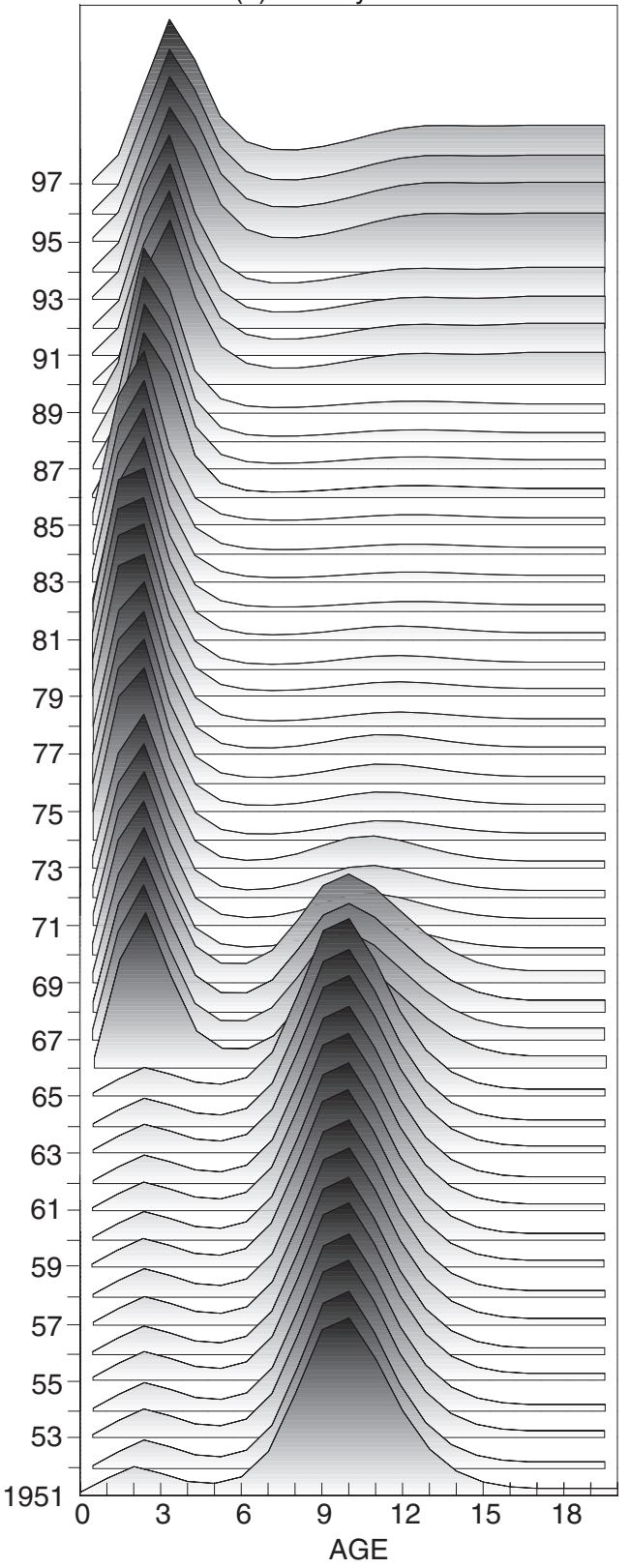

Fig. 7: Time-series plot of changes in (a) the selectivity pattern $\left(H_{t a}^{1}\right)$ for the Reference case, Japanese longline fishery in Areas 3-9 and (b) for the fishery balance $\left(H_{t, a}^{2}\right)$. Note that, for any year, the mean age-effect of selectivity is 1.0 

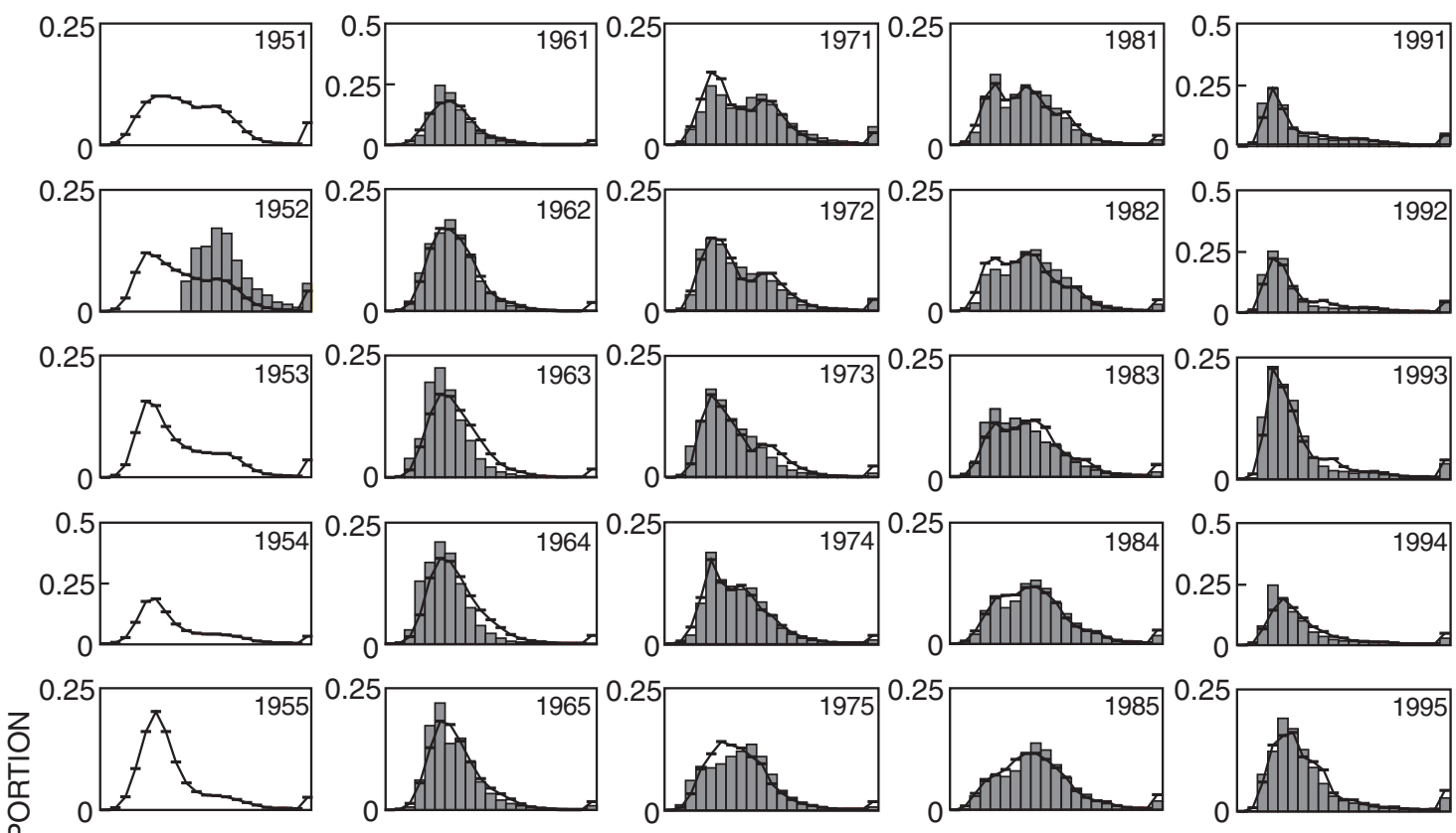

(ำ

$\frac{r}{2} 0.5$
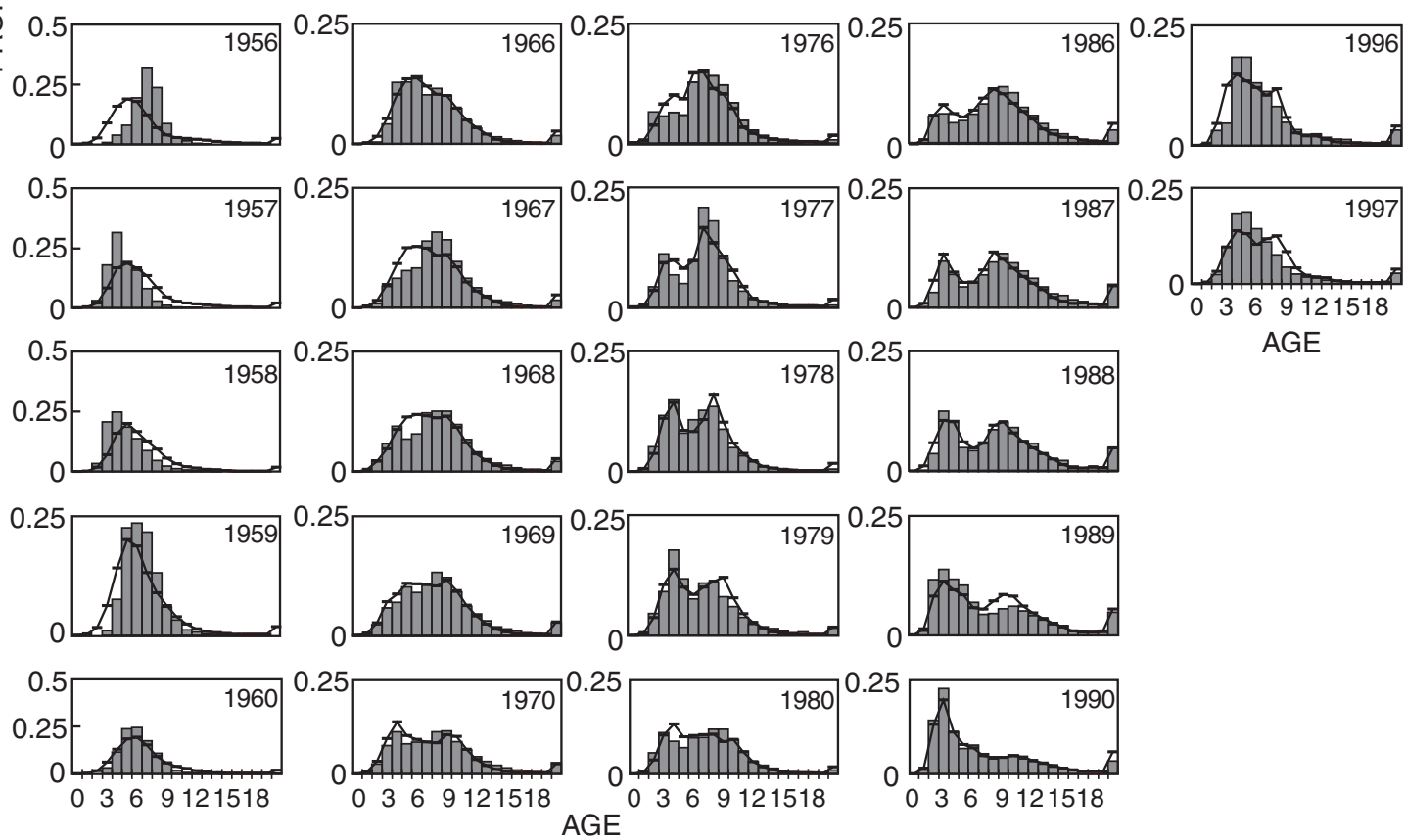

Fig. 8: Fits to catch-at-age proportion data (bars = observations, lines = model predictions) for the Reference case, Japanese longline fishery data 


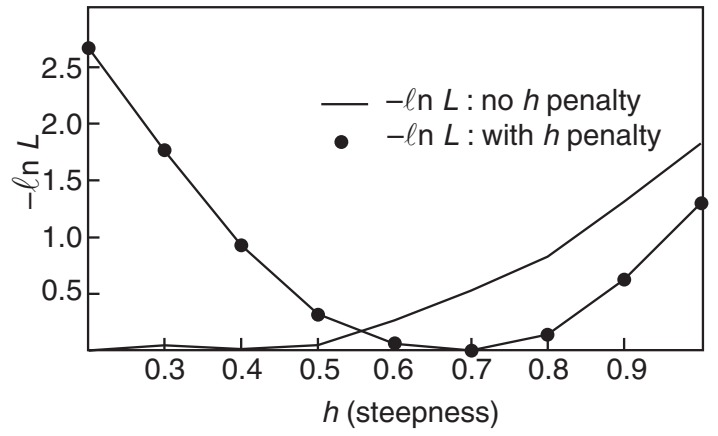

Fig. 9: Plot of negative log-likelihoods $(-\ell \mathrm{n} L)$ with and without a penalty on steepness $(h)$ for the Reference case. Note: $-\ell$ n $L$ values given for each curve are relative to the lowest value of $-\ell n L$ over the set of values of $h$ considered for that curve

higher values.

These arguments, in turn, rest on the appropriateness of the selection of "input" variance values, which can be evaluated by contrasting the inputs with their corresponding "outputs" (root mean square error) values, or effective sample sizes in the cases of age-related information) in Tables II and III. In broad terms, agreement is good. Exceptions are the selectivity-atage curvature penalty, where there appears to be overweighting, and the commercial catch-at-age data, for which the reverse applies. (Note that the lower "output" values for $\sigma_{G}$ are not at issue here. As explained following Equation 4, "input" $\sigma_{G}$ values were deliberately set high so little constraint was imposed that might have mitigated against matching observed and predicted total catch numbers each year.) In defense of maintaining the original choices in these two instances, it is argued that sharp changes in selectivity with age do not seem realistic and so should remain somewhat heavily penalized (note also that the associated terms do not greatly influence the estimation of $h$ ); on the other hand, it would seem inappropriate to accord much greater weight to the commercial catchat-age data, given uncertainties about changing somatic growth rates over time and the (necessary) use of the crude method of cohort-slicing to obtain the data.

Figures 10 and 11 show how estimates of spawning biomass and recruitment time-trends, and of the fitted stock-recruitment curve, change for different fixed values of $h$ for the Reference case. A feature of these plots - evident also in many of the other examinations of sensitivity that follow - is that recruitment is better determined than spawning biomass. This is essentially a consequence of the backwards convergence property of VPA in situations other than when the impact of fishing on a cohort is relatively light. For the spawning biomass, relative trends are better determined than absolute values.

\section{Sensitivity tests}

A number of sensitivity tests to the Reference case specification have been conducted. The first of these ("Selectivity reference Age $=5$ ") changes the choice of Age 8 (see Equation 10) to Age 5 for the age for which the Areas 3-9 longline fishery selectivity is assumed to be time-invariant. The second ("Age-atmaturity $=12$ years") changes the effective age at first spawning from 8 to 12 years, whereas the third ("Down-weight early data") down-weights the less reliable pre-1965 catch-at-age data. Then the Reference case is replicated for the alternative V2 and V9 specifications for natural mortality-at-age shown in Table I. These changes generally result in effects in the directions which would be expected, none of them substantial in size.

Alternative choices for the interpretation of cpue information do, however, make an important difference. Although results for the "constant squares" and "geostatistical" interpretations are near identical, those for "variable squares" are very different, showing higher historic recruitment levels and spawning biomasses that are considerably larger in absolute terms (see Figure 12). More important though is that the "variable squares" computations lead to a steepness estimate $h$ $=0.2$ (see Table III), even given the addition of the steepness penalty function to the analysis. In other words, this interpretation of the cpue information points to the biologically implausible conclusion (in terms of the assessment paradigm pursued here) that the SBT resource cannot provide any sustainable yield.

\section{Comparison with ADAPT assessments}

First, the implications of imposing on the Reference case the constraint (implicit in ADAPT applications) of time-invariant longline selectivity are considered. Results do not change greatly - see Figure 13 and "Constant selectivity" results in Table III. However, the corresponding fit to the срие data indicates a notable lack of fit for Ages 5 and 12+ (Fig. 14). This contrasts with the relatively good fits in Figure 5, indicating that only seemingly small changes in the selectivity pattern of the longliners over time (Fig. 7) are needed to reconcile these cpue data with the population model.

Two variants of the ADAPT analogue described 


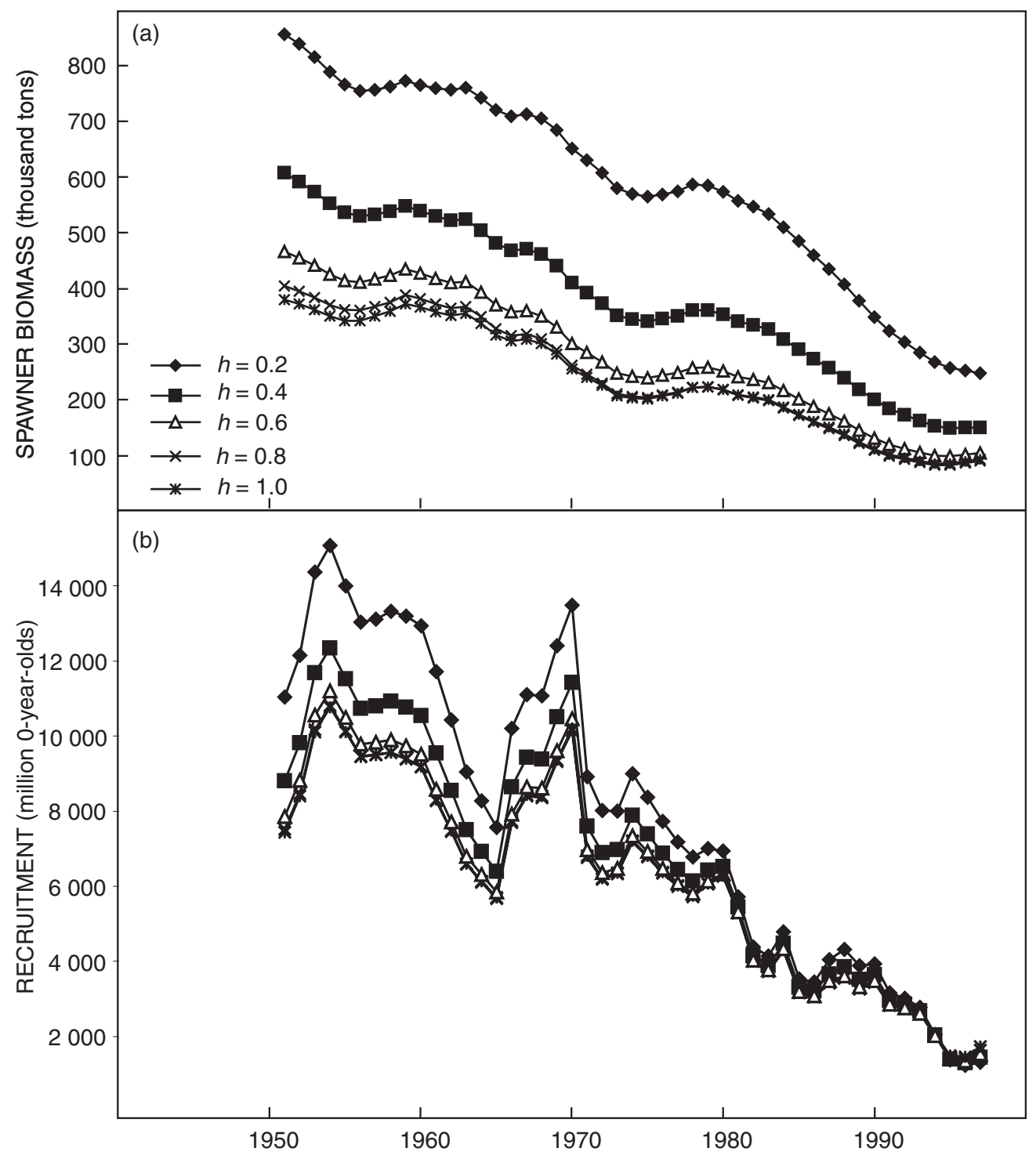

Fig. 10: Plots of (a) spawning biomass and (b) recruitment estimates by year for different values of steepness for the Reference case. The results for $h=0.8$ are omitted from (b) because they scarcely differ from those for $h=1.0$

above have been implemented. The first (“ADAPT") uses Equation 11 to relate longline cpue indices to abundances, i.e. it takes account of the estimated time-varying selectivity function in the relationship (but with selectivity standardized at Age 8). The second ("ADAPT*") follows the more normal procedure in ADAPT assessments of ignoring this selectivity, i.e. omitting all the $H_{t, a}^{1}$ terms from Equation 11, and sim- 


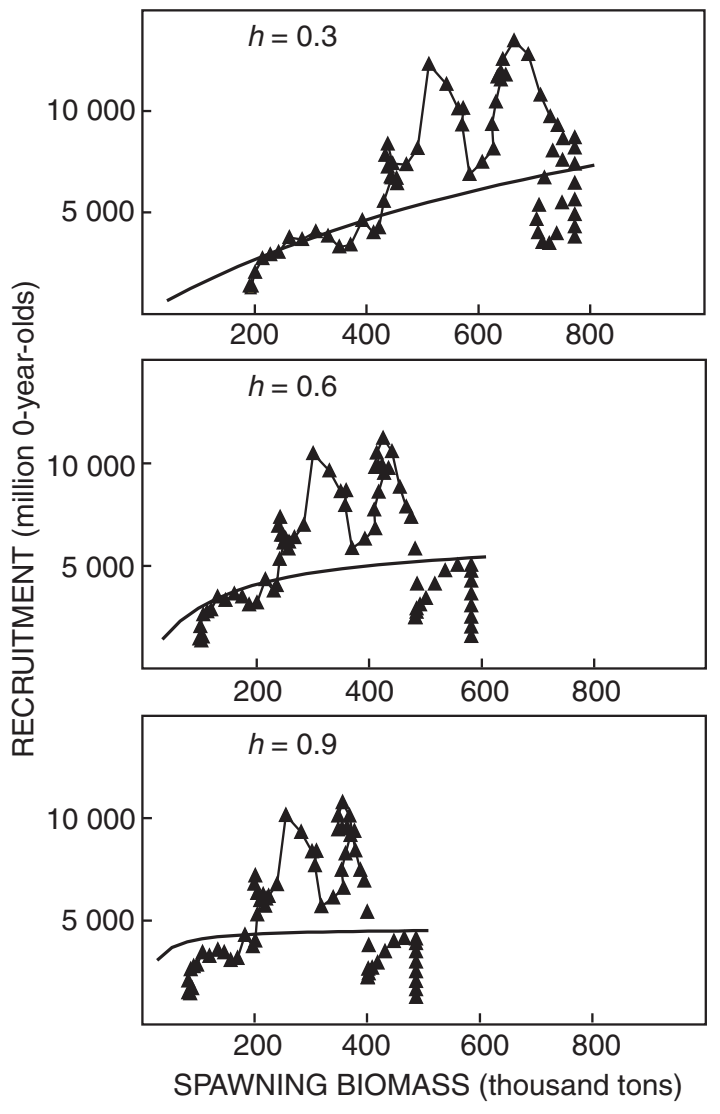

Fig. 11: Reference case plots of stock-recruitment estimates and fitted curves for different fixed values of steepness $(h)$

ply summing over numbers-at-age for the pertinent age range. The estimated recruitment trends for these ADAPT analogues are quite similar to those for the Reference case, except that they manifest greater steadiness over recent years (see Fig. 15). However, the estimated spawning biomass trends are rather different, the ADAPT results suggesting that the decline in SBT spawning biomass has been arrested earlier, since about 1990. Nevertheless, the longline selectivity patterns implied by these ADAPT analogues (see Fig. 16 for the "ADAPT" case) show changes over time, which seem to manifest an unrealistic degree of variability, suggesting that the Reference case results are perhaps more reliable.
These differences point to the importance of separating out the ages in what the ADAPT assessments have treated as a plus-group. Unless this is done, no direct account can be taken of the information on the age distribution of the spawning stock. Ensuring consistency between this age information and that inferred for the fishery helps to estimate the shape of the longline selectivity function for larger ages, and demonstrates in the case of SBT that the older fish are much less available to current Japanese longline operations.

\section{Estimates of MSY and MSYL}

Given that this assessment procedure provides estimates of stock-recruitment function parameters, it can as well produce estimates of maximum sustainable yield $(M S Y)$ and the corresponding level for spawning biomass $\left(B_{m s y}\right)$, which can also be expressed as the $M S Y$ level $(M S Y L)$ when reported as a fraction of the estimated pristine equilibrium spawning biomass. $M S Y$ and MSYL depend, of course, on the pattern of fishing selectivity-at-age applied. For the results quoted here, the same selectivity-at-age vector has been used as is estimated (for the corresponding assessment) to apply to all the fisheries (longline and balance combined) for the final year (1997) considered in those assessments.

The results, with standard errors computed as described above, are shown in Table IV, which includes comparisons of the estimated most recent (1997) and 1980 spawning biomass levels to $B_{m s y}$. Table IV gives results for the Reference case and for various fixed values of steepness parameter $h$, and Figure 17 shows plots of the resultant sustainable yield curves as a function of fishing mortality and of spawning biomass for some of these cases, including the "best" estimate of $h=0.67$ provided by maximizing the likelihood. What is very clear from the Table and Figure is the strong dependence of sustainable yield (and hence $M S Y$ ) estimates on the value for $h$. The higher the $h$, the larger the yields, and hence the better the recovery prospects for the resource.

Table IV also provides similar results for the various sensitivities to the Reference case examined earlier in this paper. Some of these results (including, importantly, that for the "variable squares" сриe interpretation) reflect an estimate of $h$ of 0.2 , and hence a zero $M S Y$ and an indeterminate MSYL. Note that, if $h$ is set equal to its Reference case estimate of 0.67 in the "variable squares" implementation, little difference in $M S Y$-related statistics from those for the Reference case results, e.g. the point estimate of $M S Y$ is 18500 


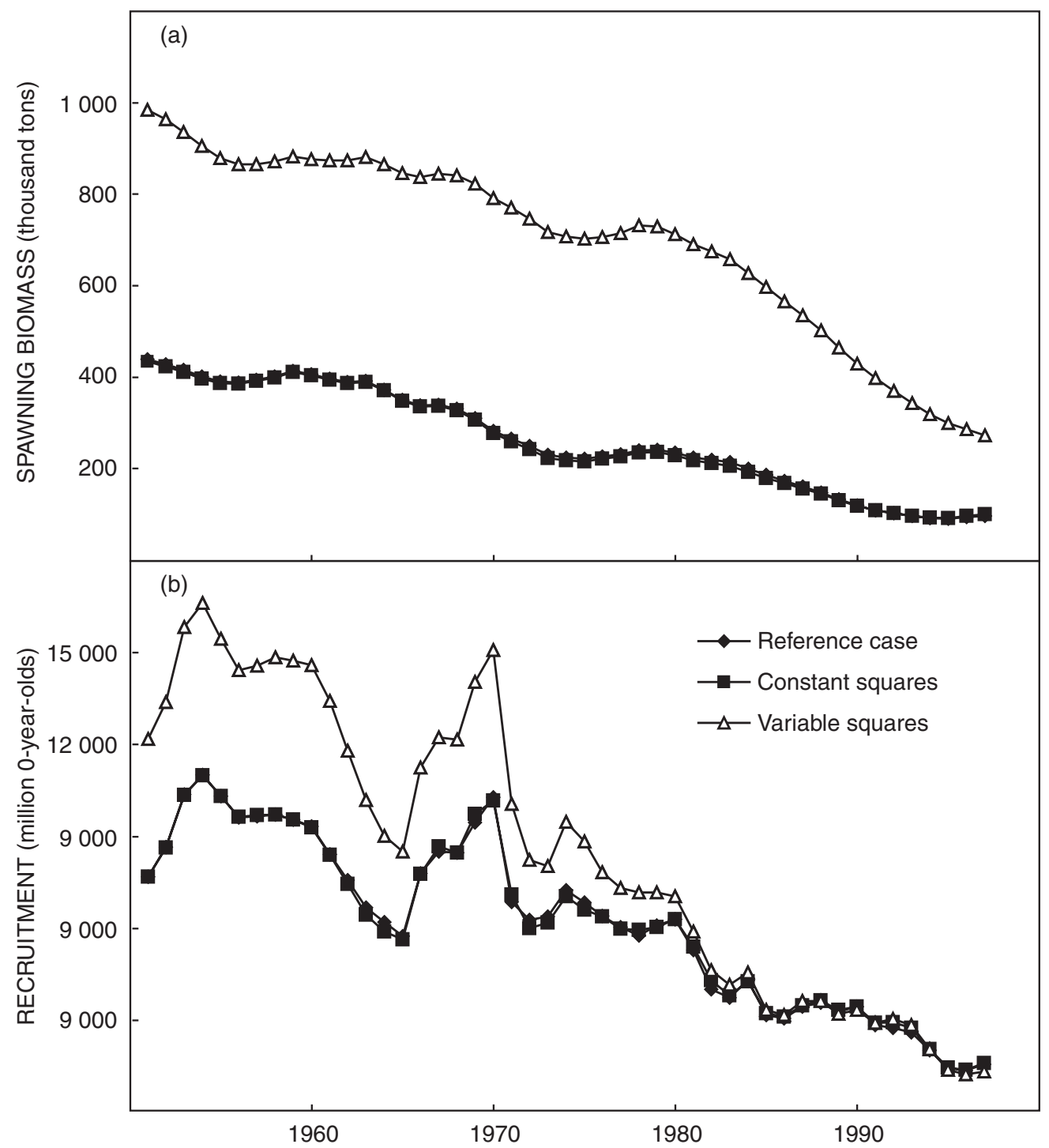

Fig. 12: Plots of (a) spawning biomass and (b) recruitment for the Reference case compared with the implementation where "constant squares" and "variable squares" cpue datasets are used. The results for "constant squares" hardly differ from those for the Reference case

tons compared with 19700 tons for the Reference case. The difference in $-\ell \mathrm{n} L$ for the $h=0.2$ and $h=$ 0.67 "variable squares" implementations is only 2.4 tons, suggesting that these cpue data do not exclude the possibility of values of $h$ somewhat in excess of 0.2 , and therefore that the data also are not incompatible with non-negligible $M S Y$ values. The ADAPT analogues, with their somewhat higher estimates of $h$ than for the Reference case, correspondingly also reflect larger $M S Y$ levels. 
Table IV: Estimates of MSY-related stock status quantities for the different implementations. Note that for three cases the $M S Y L$ was indeterminate (because $h$ was estimated or fixed at or close to 0.2 , indicating no surplus production)

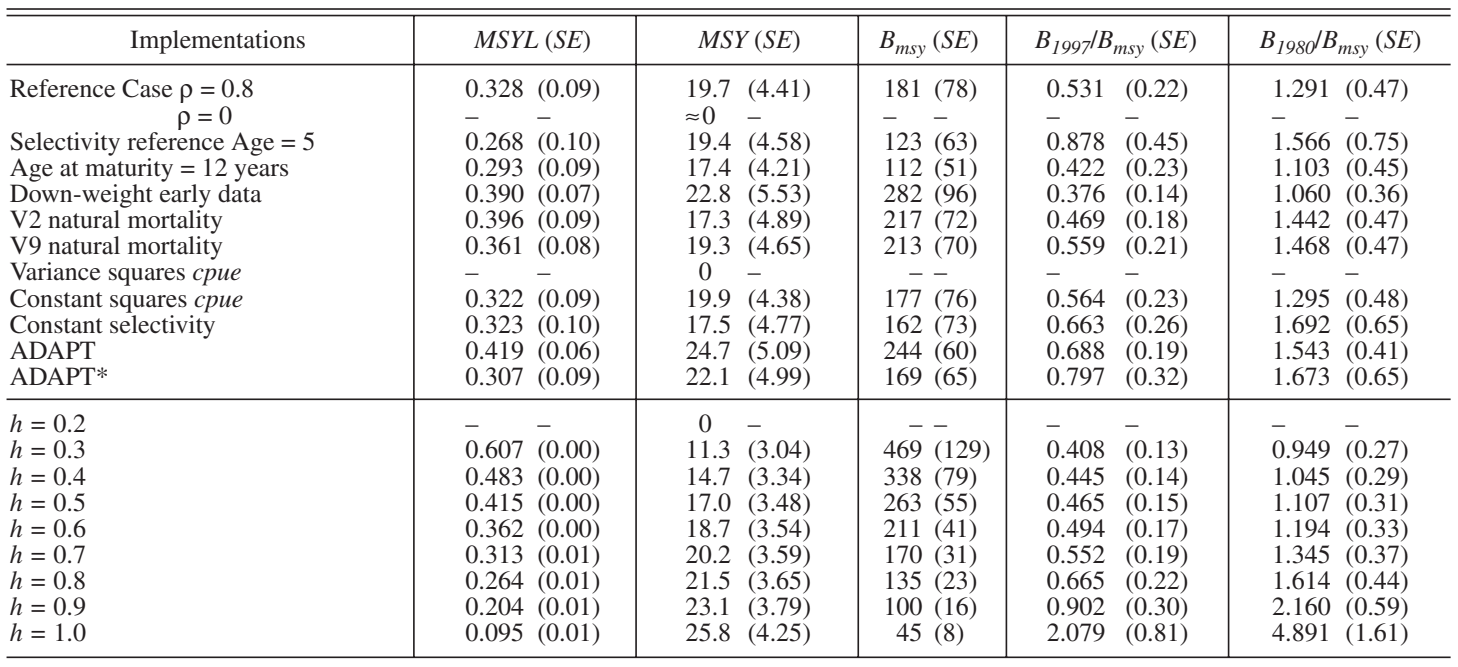

\section{Management implications}

The present CCSBT strategy for the SBT resource is to effect recovery to the 1980 spawning biomass level by 2020 . Choice of the 1980 level as target has its origin in an informal meeting of Australian, Japanese and New Zealand scientists in 1982. At that time, VPAs suggested that SBT recruitment levels had been near maintained, despite an estimated (catch-induced) reduction of the spawning biomass in 1980 to about one-third of its 1960 level. Given large catches of young tuna, particularly by Australia, during the 1970s, a further reduction in spawning biomass was projected, and it was recommended by the scientists at that 1982 meeting as desirable to attempt to recover the resource to the 1980 spawning biomass level. This was to guard against the possibility of "recruitment overfishing" (reduced recruitment at low spawning biomass).

Table IV provides a basis to compare this choice of the 1980 spawning biomass level as a recovery target with $B_{m s y}$ (a level to which UNCLOS advocates the restoration of depleted populations). The point estimates of $B_{1980} / B_{m s y}$ in Table IV are nearly all above 1 , some considerably so. This suggests that a recovery target set as the 1980 spawning biomass level may be unnecessarily high, so a review of this choice by the CCSBT might be merited.

The estimates of the most recent (1997) spawning biomass expressed as a fraction of $B_{m s y}$ are effectively all below 1, confirming the interpretation of the SBT resource as below its $M S Y L$, so harvest levels are desirably set to achieve resource rebuilding. However, the point estimates of $B_{1997} / B_{m s y}$ are generally above 0.5 (indeed for the reference age for constant selectivity for the longline cpue set to 5 - case "Selectivity reference Age = 5" - the estimate is as high as 0.87). This suggests that, although this most recent status of the resource does reflect depletion below its $M S Y L$, the extent of this is certainly not catastrophic. Comparison of recent catches with the sustainable yield levels suggested by the plots in Figure 17 indicates that rebuilding to $M S Y L$ should be achievable without major disruption of the fishery.

This last statement is, of course, conditional on the "geostatistical" cpue interpretation upon which most of the results in Table IV are based. Use of the "constant squares" interpretation instead would make little difference, but the "variable squares" interpretation, with its best estimate of $h$ of 0.2 , suggests otherwise, with rebuilding impossible in the absence of any sustainable yield capability for the resource. Both the biological lack of reality of such a conclusion, and the clear intent of the "variable squares" interpretation of the cpue data to provide a lower bound rather than a realistic scenario, argue against giving this "variable squares" result, of itself, undue import. However, the 


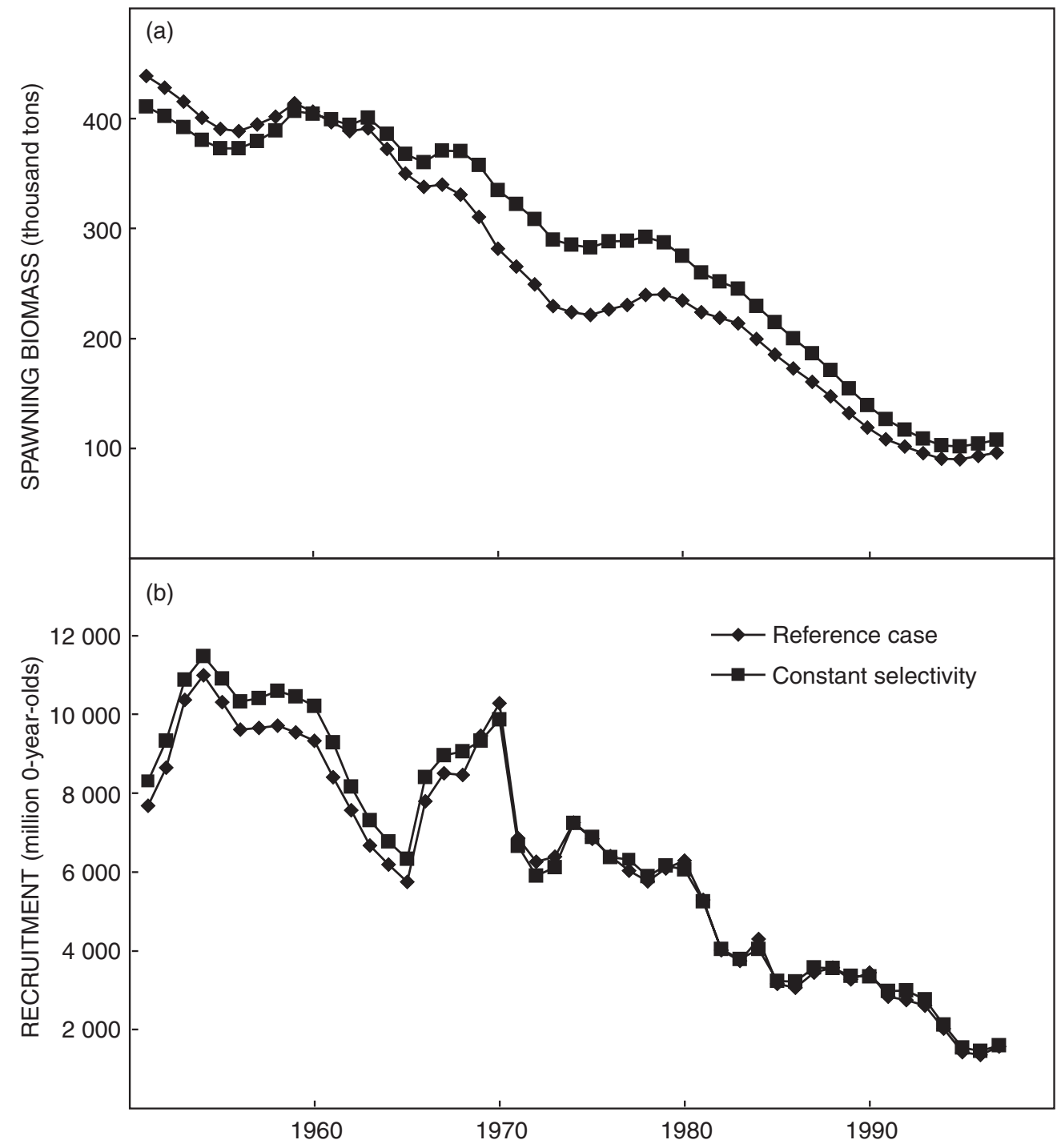

Fig. 13: Plots of (a) spawning biomass and (b) recruitment for the Reference case compared with the implementation where longline selectivity is held constant over time

"constant squares", and possibly also the "geostatistical", interpretations of the cpue data (and consequently the associated sustainable yield estimates) may be over-optimistic, so it would seem important to attempt to refine perceptions of where a more realistic lower bound might lie between the "constant squares" and "variable squares" extremes, to facilitate prudent management of the SBT resource. 

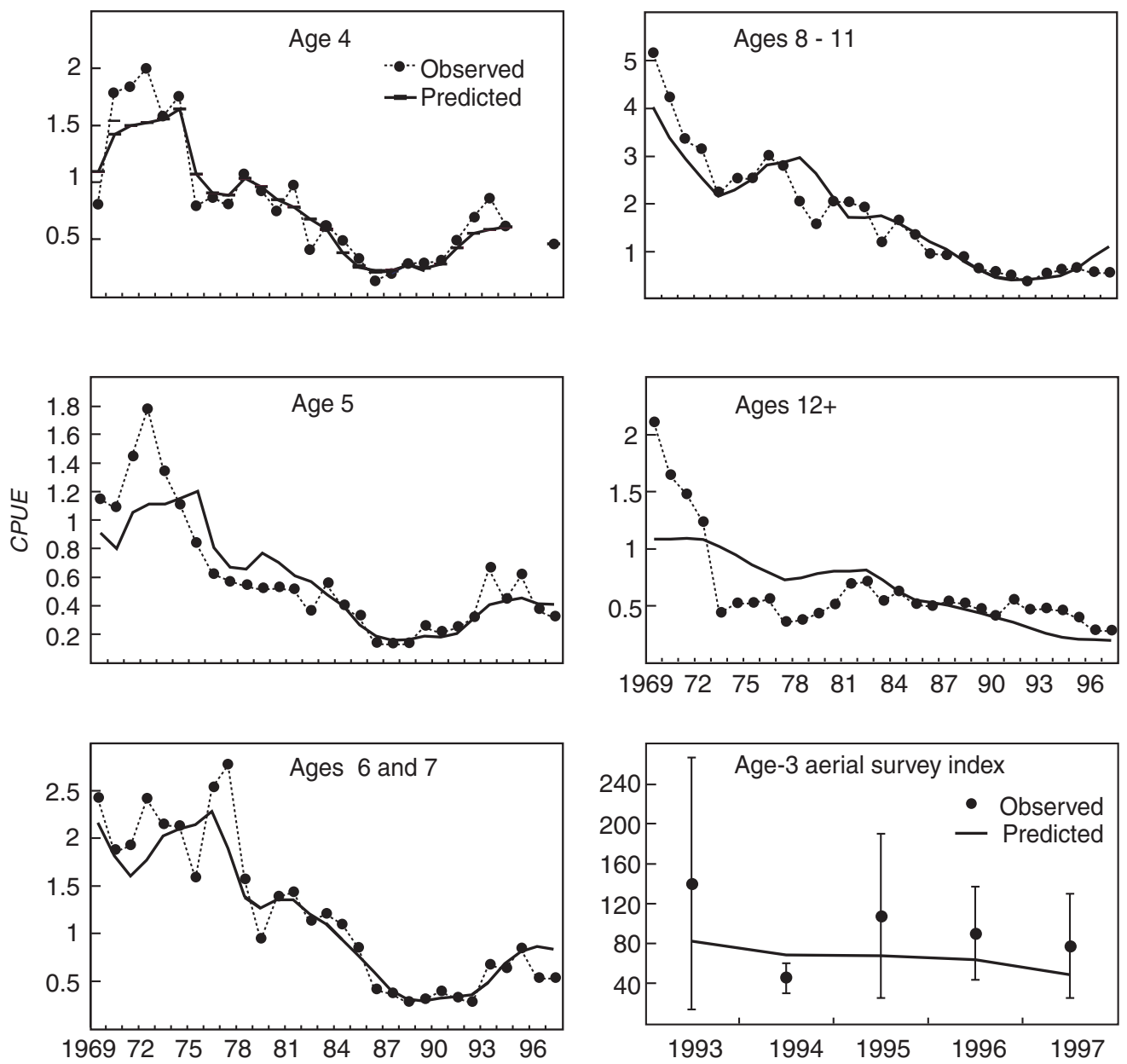

Fig. 14: Fit to longline cpue indices and Age-3 aerial survey index for the case where longline selectivity is held constant over time

\section{CONCLUSIONS}

The historic SBT recruitment and spawning biomass trends estimated in this analysis are not qualitatively different from those developed in the CCSBT SC, but they are suggestive of somewhat larger spawning biomasses in absolute terms.

However, the key parameter value required to pro- vide reliable estimates of sustainable yields and recovery prospects for the resource is that for stockrecruitment steepness, $h$. For the "geostatistical" and "constant squares" interpretations of the cpue data, at least, the totality of the data available for assessment purposes contains very little information on the value of $h$, and it therefore seems desirable to add information to the estimation process in the form of a penalty function for the value for $h$, which is based on esti- 


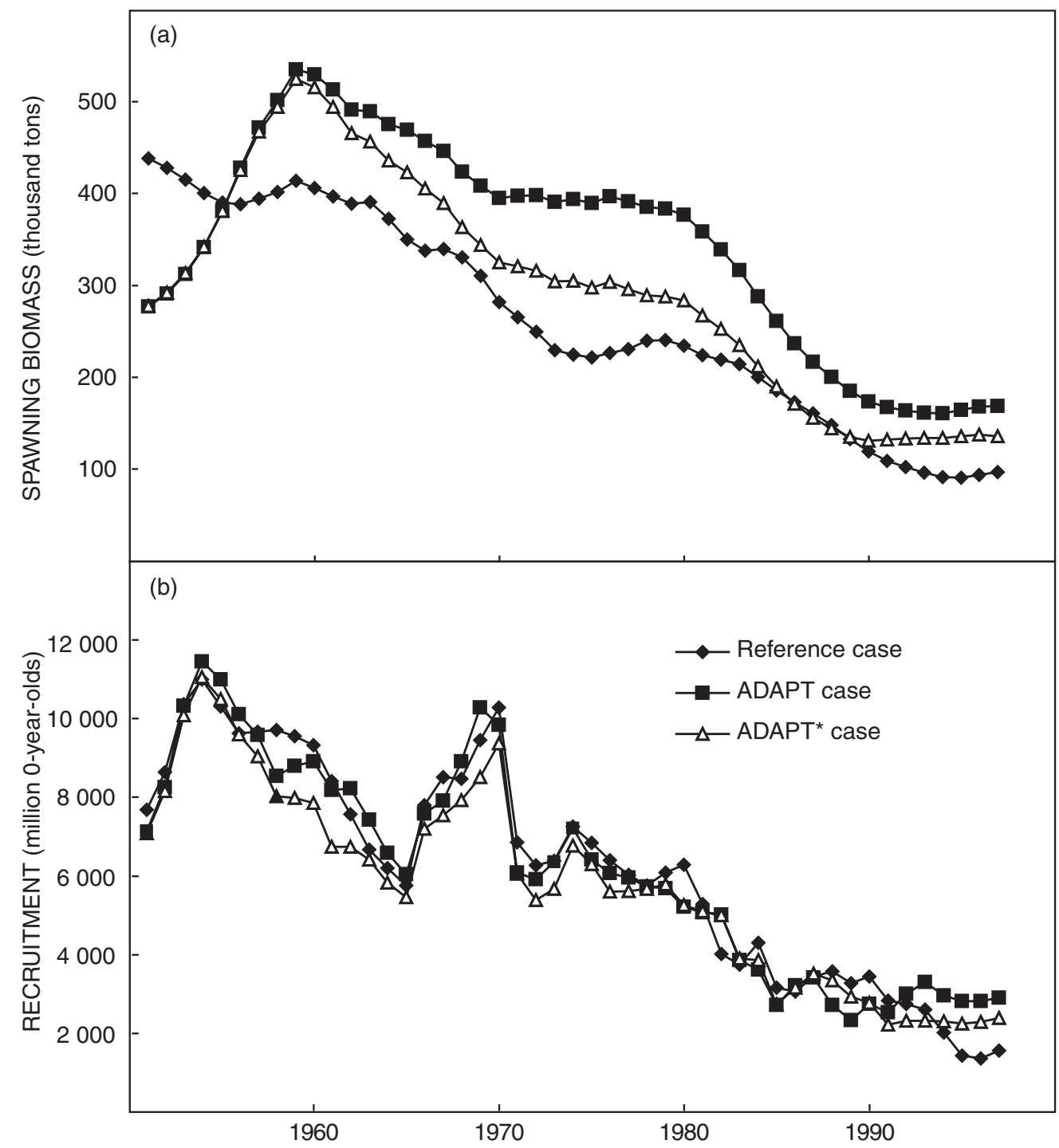

Fig. 15: Plots of (a) spawning biomass and (b) recruitment for the Reference case compared with the cases where the two ADAPT analogues have been implemented

mates for other fish populations - a procedure analogous to the use of a prior for $h$ in a Bayesian formulation of this assessment. The poor precision with which $h$ and hence productivity can be estimated from the data for SBT alone without recourse to this prior is a reflection of the "one-way trip" (Hilborn 1979) nature of these data. With the primary index of resource abundance (the cpue data) essentially showing 


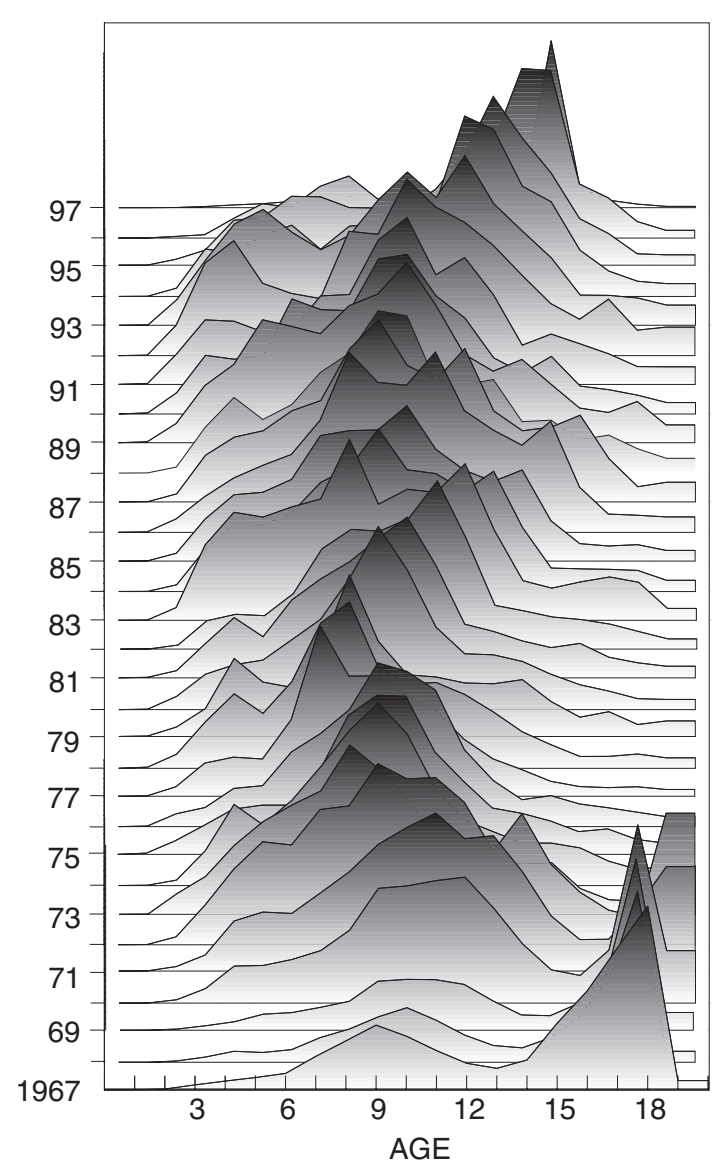

Fig. 16: Longline selectivity estimated for the ADAPT case, 1967-1997

a downward trend without a general and sustained subsequent upturn, assessment methods are unable to distinguish what the relative contributions of standing stock reduction and surplus production have been to historic catches, and are hence unable to estimate sustainable yield levels precisely.

The present practice within the CCSBT SC of estimating the parameters of the stock-recruitment function external to the assessment process, rather than internally as in this analysis, merits review. In particular, the estimation needs to make due allowance for the high serial correlation evident in the residuals about the estimated stock-recruitment function, so that this information is not given undue weight when estimating $h$ (in particular). This, together with the notably different spawning biomass trends that result from the ADAPT analogue implementations of this approach (that ignore the possibility of errors in the catch-at-age data and considerations of likely smoothness in the longline selectivity pattern over time) are key results of this work, which have likely wider pertinence than to the assessment of the SBT resource alone.

Of a number of sensitivities investigated, clearly the one to which results are the most sensitive is the difference between the "geostatistical" (and "constant squares") interpretations of the cpue information and that of "variable squares". The extreme "variable squares" interpretation, particularly given its associated point estimate of zero sustainable yield, does not seem plausible. However, prudent management would seem to require attempts to refine perceptions of where a more realistic lower bound might lie between the "constant squares" and "variable squares" extremes, so as (in turn) to provide lower bounds for sustainable yield estimates.

The assessment method applied in this paper indicates that, viewed in terms of point estimates of the biomass level yielding $M S Y\left(B_{m s y}\right)$, and under the "geostatistical" (and "constant squares") cpue interpretations, the SBT resource is certainly below $B_{m s y}$, but not catastrophically so. The target recovery level for the spawning biomass (the 1980 level) currently adopted by the CCSBT appears to be above $B_{m s y}$, and hence merits review. Nevertheless, a number of the observed (e.g. plus-group cpue) and inferred (e.g. recruitment) indices of stock status are at or close to all time lows, pointing again to the need for prudent management at this time.

It is emphasized, however, that no claim is intended that the method developed in this paper is necessarily the only or the best possible for application in assessing SBT. Certainly, the results of this work need to be contrasted with those of other possible approaches, and the defensibilities of their differing assumptions. Nevertheless, these analyses are seen as having made important advances on the assessment method employed in the CCSBT SC in the past, and hence it is considered that they merit consideration in future management debates concerning the resource. An obvious extension of this approach is to apply it directly to length-based data, together with models of annual somatic growth and its variability. This would avoid the intermediate and somewhat unsatisfactory approach of using cohort slicing to convert primary observations in terms of lengths into ages. An initial application of such an approach to SBT is reported in Kolody and Polacheck (2001a, b). 

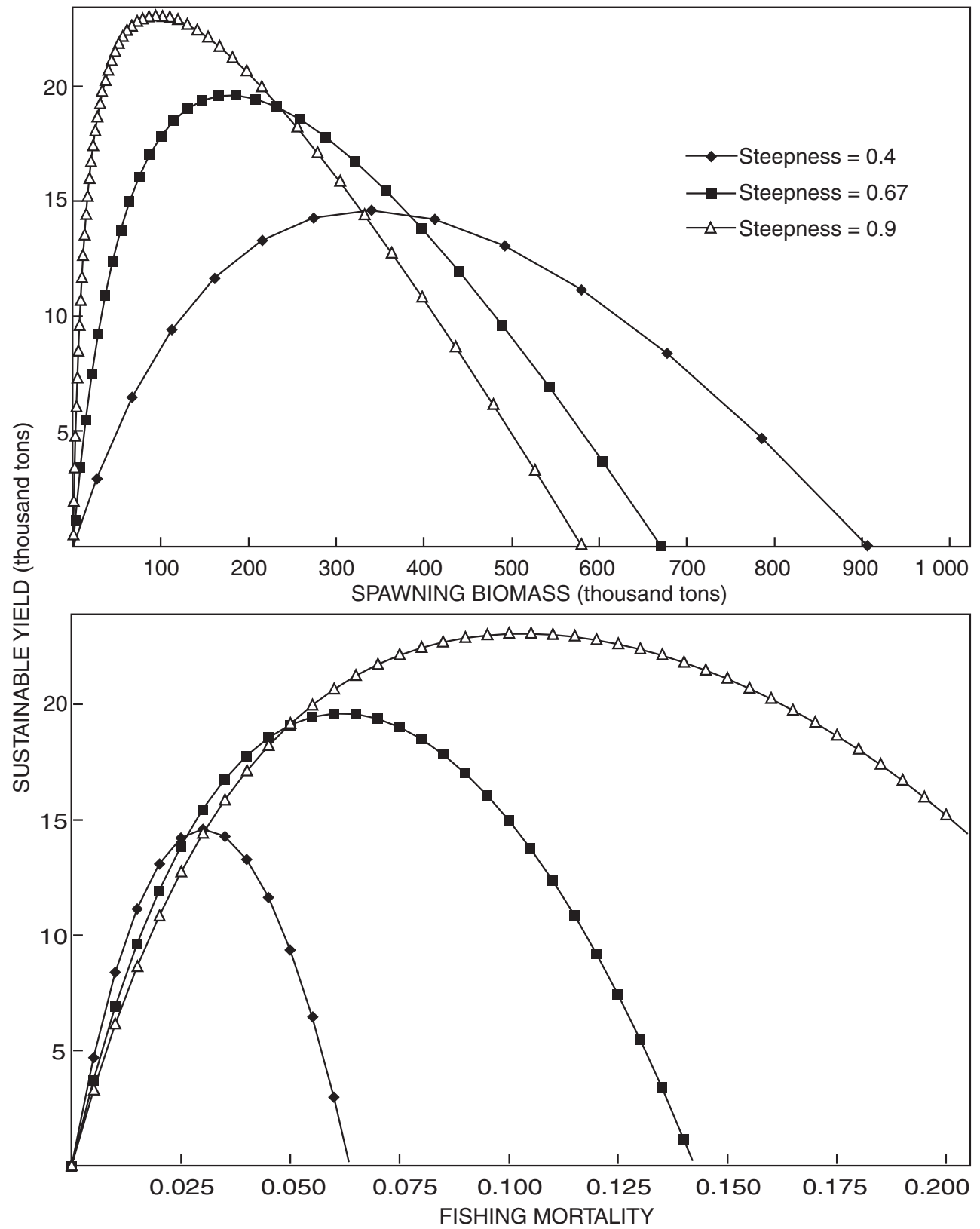

Fig. 17: Example sustainable yield v. spawning biomass and v. fishing mortality (on Age 8) plots for three values of stock-recruitment steepness parameter $(h)$ for the Reference case. The selectivity pattern for the whole fishery, as estimated to have applied in 1997, is assumed to apply for these computations 


\section{ACKNOWLEDGEMENTS}

Drs Y. Takeuchi and S. Tsuji (National Research Institute of FarSeas Fisheries, Japan) and Mr J. Gunn (Commonwealth Scientific and Industrial Research Organisation [CSIRO], Australia) are thanked for respectively sending us the encoded fisheries and spawning stock age-composition data, and Ms A. Preece (CSIRO, Australia) for advice on model inputs. The Joint Tuna Industries of Australia, Japan and New Zealand kindly provided travel support funding to facilitate this work. The estimation software used, AD Model Builder, is a trademark of Otter Research Ltd, P. O. Box 265, Station A, Nanaimo, B.C. V9R 5K9, Canada. The comments of Drs J. Collie (University of Rhode Island), D. Conover (State University of New York, Stony Brook), X. He (CSIRO, Australia) and T. Miller (University of Maryland) and Prof. T. J. Quinn (University of Alaska, Fairbanks) on an earlier version of this paper are gratefully acknowledged.

\section{LITERATURE CITED}

CATON, A. E. 1991 - Review of aspects of southern bluefin tuna biology, population and fisheries. In World Meeting of Stock Assessments of Bluefin Tunas: Strengths and Weaknesses. Deriso, R. B. and W. H. Bayliff (Eds). Spec. Rep. Inter-Am. trop. Tuna Commn 7: 181-357.

COWLING, A. [M.] and C. [P.] MILLAR 1998 - Data analysis of the aerial survey (1991-1998) for juvenile southern bluefin tuna on the Great Australian Bight. Commission for the Conservation of Southern Bluefin Tuna Doc. CCSBT/SC/9807/8: $62 \mathrm{pp}$.

DERISO, R. B., QUINN, T. J. and P. R. NEAL 1985 - Catch-age analysis with auxiliary information. Can. J. Fish. aquat. Sci. 42(4): $815-824$

FOURNIER, D. [A.] and C. P. ARCHIBALD 1982 - A general theory for analyzing catch at age data. Can. J. Fish. aquat. Sci. 39(8): 1195-1207.

FOURNIER, D. A., HAMPTON, J. and J. R. SIBERT 1998 MULTIFAN-CL: a length-based, age-structured model for fisheries stock assessment, with application to South Pacific albacore, Thunnus alalunga. Can. J. Fish. aquat. Sci. 55: 2105-2116.

FRANCIS, R. I. C. C. 1992 - Use of risk analysis to assess fishery management strategies: a case study using orange roughy (Hoplostethus atlanticus) on the Chatham Rise, New Zealand. Can. J. Fish. aquat. Sci. 49(5): 922-930.

GAVARIS, S. 1988 - An adaptive framework for the estimation of population size. Res. Doc. Can. Atl. Fish. scient. Adv. Comm. (CAFSAC) 88/29: 12 pp.

GELMAN, A., CARLIN, J. B., STERN, H. S. and D. B. RUBIN 1995 - Bayesian Data Analysis. London; Chapman \& Hall: $247 \mathrm{pp}$.

GEROMONT, H. F. and D. S. BUTTERWORTH 2001 - Possible extensions to the ADAPT VPA model applied to western north Atlantic bluefin tuna, addressing in particular the need to account for "additional variance". Coll. Vol. Sci. Pap. int. Commn Conserv. Atl. Tuna 52: 1663-1705.
GREIWANK, H. F. and G. F. CORLISS (Eds) 1991 - Automatic differentiation of algorithms: theory, implementation, and application. In Proceedings of the Society for Industrial and Applied Mathematics Workshop on the Automatic Differentiation of Algorithms, Breckenridge, Philadelphia, Colorado, January 1991. Society of Industry and Applied Mathematics.

GUDMUNDSSON, G. 1994 - Time series analysis of catch-atage observations. Appl. Statist. 43: 117-126.

GUNN, J. S., DAVIS, T. L. O., FARLEY, J. H., CLEAR, N. P. and K. A. HASKARD 1996 - Preliminary estimates of the age structure of the SBT spawning stock (including a revised estimate of the age at first spawning). Commission for the Conservation of Southern Bluefin Tuna Doc. CCSBT/ SC/96/10: 27 pp.

GUNN, J. [S.], POLACHECK, T , PREECE, A. [L.], RICARD, D. [G.], EVESON, [J.] P., DAVIS, T. [L.] [O.], FARLEY, J. [H.], KLAER, N. [L.] and D. [S.] KOLODY $2001-$ Fishery indicators for the SBT stock: 2001. Commission for the Conservation of Southern Bluefin Tuna Doc. CCSBT/SC/0108/25: $31 \mathrm{pp}$

HAIST, V., FOURNIER, D. A and J. F. SCHWEIGART $1993-$ Estimation of density-dependent natural mortality in British Columbia herring stocks through SSPA and its impact on sustainable harvesting strategies. In Risk Evaluation and Biological Reference Points for Fisheries Management. Smith, S. J., Hunt, J. J. and D. Rivard (Eds). Can. spec. Publ. Fish. aquat. Sci. 120: 269-282.

HILBORN, R. 1979 - Comparison of fisheries control systems that utilize catch and effort data. J. Fish. Res. Bd Can. 36(12): 1477-1489.

HILBORN, R. and D. S. BUTTERWORTH 1996 - Fitting the 1994-1995 spawner age distribution data for SBT. Commission for the Conservation of Southern Bluefin Tuna Doc. CCSBT/SC/96/34: 8 pp.

HILBORN, R., PARMA, A., MAUNDER, M., MAGUIRE, J-J. and L. REED 1998 - An assessment of the status of sablefish stock of the US Pacific coast in 1998. In Status of Pacific Coast Groundfish Fishery through 1998 and Recommended Acceptable Biological Catches for 1999. Portland, Oregon; Pacific Fisheries Management Council: $1-92$.

HILBORN, R. and C. J. WALTERS 1992 - Quantitative Fisheries Stock Assessment. Choice, Dynamics and Uncertainty. New York; Chapman \& Hall: Xv + 570 pp.

KOLODY, D. [S.] and T. POLACHECK 2001a - Application of a statistical catch-at-age and -length integrated analysis model for the assessment of southern bluefin tuna stock dynamics 1951-2000. Commission for the Conservation of Southern Bluefin Tuna Doc. CCSBT/SC/0108/13: 43 pp.

KOLODY, D. [S.] and T. POLACHECK 2001b - A statistical catch-at-age/length integrated analysis model for southern bluefin tuna stock assessment. Commission for the Conservation of Southern Bluefin Tuna Doc. CCSBT/SC/ 0108/27: $28 \mathrm{pp}$

MACE, P. M., and I. J. DOONAN 1988 - A generalized bioeconomic simulation model for fish population dynamics. New Zealand Fisheries Assessment Research Doc. 88/4: 52 pp.

McALLISTER, M. K. and J. N. IANELLI 1997 - Bayesian stock assessment using catch-age data and the sampling-importance resampling algorithm. Can. J. Fish. aquat. Sci. 54: 284-300.

METHOT, R. D. 1990 - Synthesis model: an adaptable framework for analysis of diverse stock assessment data. In Proceedings of the Symposium on Applications of Stock Assessment Techniques to Gadids. Low, L. (Ed.). Bull. Int. N. Pacif. Fish. Commn 50: 259-277.

POLACHECK, T., BETLEHEM, A. [W.] and A. [L.] PREECE 1997b - Documentation of the Virtual Population Analysis methods and model inputs used for estimating 
current and historical stock sizes of southern bluefin tuna population for the third CCSBT Scientific Committee Meeting. Commission for the Conservation of Southern Bluefin Tuna Doc. CCSBT/SC/97/24: 44 pp.

POLACHECK, T., HEARN, W. [S.], MILLAR, C. [P.] and C. [A.] STANLEY 1998 - Updated estimates of mortality rates for juvenile SBT from multi-year tagging cohorts. Commission for the Conservation of Southern Bluefin Tuna Doc. CCSBT/SC/9807/20: 26 pp.

POLACHECK, T., HEARN, W. [S.], MILLER, C. [P.], WHITELAW, [A.] W. and C. [A.] STANLEY 1997c - Updated estimates of natural and fishing mortality for juvenile SBT from multi-year tagging of cohorts. 1997. Commission for the Conservation of Southern Bluefin Tuna Doc. CCSBT/ SC/9707/26: $36 \mathrm{pp}$.

POLACHECK, T., KLAER, N. L., MILLAR, C. [P.] and A. L. PREECE 1999 - An initial evaluation of management strategies for the southern bluefin tuna fishery. ICES J. mar. Sci. 56: 811-826.

POLACHECK, T. and A. [L.] PREECE 1998 - Documentation of the Virtual Population analysis methods and model input used for estimating current and historical stock sizes of southern bluefin tuna: updates and fisheries 1998. Commission for the Conservation of Southern Bluefin Tuna Doc. CCSBT/SC/9802/37: 15 pp.
POLACHECK, T., PREECE, A. [L.], BETLEHEM, A. [W.], KLAER, N. [L.] and W. [S.] HEARN 1997a - Estimation of the historical catch and its age distribution for southern bluefin tuna. Commission for the Conservation of Southern Bluefin Tuna Doc. CCSBT/SC/97/20: $30 \mathrm{pp}$.

PRESS, W. H., TEUKOLSKY, S. A., VETTERLING, W. T. and B. P. FLANNERY 1992 - Numerical Recipes in Fortran. The Art of Scientific Computing, 2nd ed. New York; Cambridge University Press: xxvi $+963 \mathrm{pp}$.

PUNT, A. E and R. HILBORN 1997 - Fisheries stock assessment and decision analysis: the Bayesian approach. Revs Fish Biol. Fish. 7: 35-63.

SAINSBURY, K. J. 1998 - Living marine resource assessment for the $21^{\text {st }}$ century: what will be needed and how will it be provided? In Fishery Stock Assessment Models. Fairbanks, Alaska; University of Alaska Sea Grant AK-SG-98-01: 1-40.

SCHNUTE, J. T. 1994 - A general framework for developing sequential fisheries models. Can. J. Fish. aquat. Sci. 51: 1676-1688.

SCHNUTE, J. T. and L. J. RICHARDS 1995 - The influence of error on population estimates from catch-age models. Can. J. Fish. aquat. Sci. 52: 2063-2077.

TSUJI, S. and Y. TAKEUCHI 1997 - Revised VPA and projection for 1996 assessment. Commission for the Conservation of Southern Bluefin Tuna Doc. CCSBT/SC/9707/31: 38 pp. 